\title{
Article
}

\section{Unraveling the Role of a Flexible Tetradentate Ligand in the Aerobic Oxidative Carbon-Carbon Bond Formation with Palladium Complexes: A Computational Mechanistic Study}

Qian Peng, Zengwei Wang, Snezana D. Zaric, Edward N. Brothers, and Michael B. Hall

Downloaded from http://pubs.acs.org on February 14, 2018

\section{Just Accepted}

"Just Accepted" manuscripts have been peer-reviewed and accepted for publication. They are posted online prior to technical editing, formatting for publication and author proofing. The American Chemical Society provides "Just Accepted" as a service to the research community to expedite the dissemination of scientific material as soon as possible after acceptance. "Just Accepted" manuscripts appear in full in PDF format accompanied by an HTML abstract. "Just Accepted" manuscripts have been fully peer reviewed, but should not be considered the official version of record. They are citable by the Digital Object Identifier (DOI®). "Just Accepted" is an optional service offered to authors. Therefore, the "Just Accepted" Web site may not include all articles that will be published in the journal. After a manuscript is technically edited and formatted, it will be removed from the "Just Accepted" Web site and published as an ASAP article. Note that technical editing may introduce minor changes to the manuscript text and/or graphics which could affect content, and all legal disclaimers and ethical guidelines that apply to the journal pertain. ACS cannot be held responsible for errors or consequences arising from the use of information contained in these "Just Accepted" manuscripts. 


\title{
Unraveling the Role of a Flexible Tetradentate Ligand in the Aerobic Oxidative Carbon-Carbon Bond Formation with Palladium Complexes: A Computational Mechanistic Study
}

\author{
Qian Peng ${ }^{1,2 *}$, Zengwei Wang' ${ }^{1}$ Snežana D. Zarić3,4, Edward N. Brothers 3 , and
}

Michael B. Hall ${ }^{2 *}$

\begin{abstract}
1. State Key Laboratory of Elemento-Organic Chemistry, College of Chemistry, Nankai University, Tianjin 300071, China. E-mail: qpeng@nankai.edu.cn

2. Department of Chemistry, Texas A\&M University, College Station, TX 77843-3255 e-mail: mbhall@tamu.edu, Tel +1-979-845-1843, Fax: +1-979-845-2971

3. Department of Chemistry, Texas A\&M University at Qatar, P.O. Box 23874, Doha, Qatar 4. Department of Chemistry, University of Belgrade, Studentski trg 12-16, Belgrade, Serbia
\end{abstract}

\begin{abstract}
:
Mechanistic details of the aerobic oxidative coupling of methyl groups by a novel $\left({ }^{\mathrm{Me}} \mathrm{L}\right) \mathrm{Pd}^{\mathrm{II}}(\mathrm{Me})_{2}$ complex with the tetradentate ligand ${ }^{\mathrm{Me}} \mathrm{L}=\mathrm{N}, \mathrm{N}$-di-methyl-2,11diaza[3.3](2,6)pyridinophane has been explored by density functional theory (DFT) calculations. The calculated mechanism sheds light on the role of this ligand's flexibility in several stages of the reaction, especially as the oxidation state of the Pd changes. Ligand flexibility leads to diverse axial coordination modes and it controls the availability of electrons by modulating the energies of high-lying molecular orbitals, particularly those with major $\mathrm{d}_{\mathrm{z}}{ }^{2}$ character. Solvent molecules, particularly water, appear essential in the aerobic oxidation of $\mathrm{Pd}(\mathrm{II})$ by lowering the energy of the oxygen molecule's unoccupied molecular orbital and stabilizing the $\mathrm{Pd}-\mathrm{O}_{2}$ complex. Ligand flexibility and solvent coordination to oxygen are essential to the required spin-crossover for the transformation of high-valent $\mathrm{Pd}^{\mathrm{X}}-\mathrm{O}_{2}$ complexes. A methyl cation pathway has been predicted by our calculations in transmetalation between $\mathrm{Pd}^{\mathrm{II}}$ and $\mathrm{Pd}^{\mathrm{IV}}$ intermediates to be preferred over methyl radical or methyl anion pathways. Combining an axial and equatorial methyl group is preferred in the reductive elimination pathway where roles are played by the ligand's flexibility and the fluxionality of trimethyl groups
\end{abstract}




\section{INTRODUCTION}

Ring flipping as defined by the conformational analysis of cyclohexane, is a interconversion phenomenon arising from low barrier rotations about single bonds in this cyclic molecule ${ }^{1}$. Ring flipping in multidentate flexible ligands enables the formation of complexes with variable coordination numbers. Although ligand flexibility, to one degree or another, often occurs in coordination chemistry, little attention has been focused on how such conformational changes might lead to significant effects on the chemistry. An exception is the evolution of the DuBois catalyst, ${ }^{2}$ a well-known $\mathrm{H}_{2}$ catalyst, where each of several coordination spheres of the active $\mathrm{Ni}$ core and their flexibility play a crucial role in the efficiency (TOF increase from $<0.2 \mathrm{~s}^{-1}$ to $1.1 \times 10^{5} \mathrm{~s}^{-1}$ ).

Scheme 1. A) Proposed catalytic cycle for Pd-catalyzed methyl dimerization; B) examples of complexes performing aerobic oxidation of $\mathrm{Pd}^{\mathrm{II}} \mathrm{Me}$

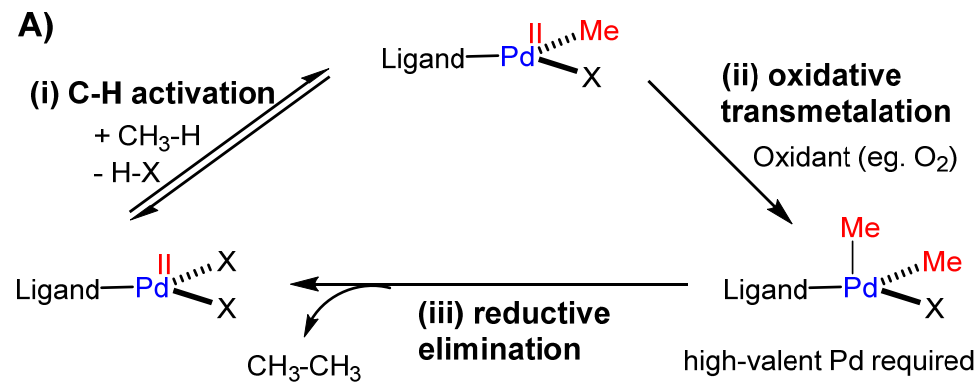

B) Oxidative transmetalation by $\mathrm{O}_{2}$
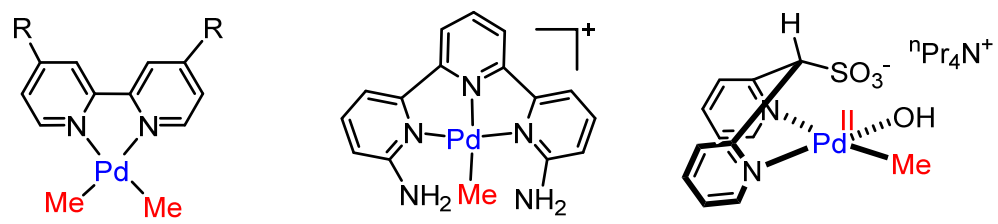

Although the catalytic oxidative coupling of methane is an attractive route to ethane and higher hydrocarbons ${ }^{3}$, such oxidation reactions with molecular oxygen are rare; rarer still are studies on how ligand flexibility might improve such industrially important reactions. Palladium complexes have been widely applied as efficient catalysts 
for the $\mathrm{C}-\mathrm{C}$ coupling reactions in synthetic chemistry. ${ }^{4}$ The vast majority of these reactions involve $\mathrm{Pd}^{\mathrm{o}} / \mathrm{Pd}^{\mathrm{II}}$ catalytic cycles with assistance of either a functionalized substrate $^{5}$ or a sacrificial oxidant ${ }^{6,7 a}$. Molecular oxygen, as an environmentally friendly and inexpensive oxidant, is a desirable reagent for a variety of oxidative organic transformations ${ }^{7-8}$. Although various high-valent oxidants $\left(\mathrm{Pd}^{\mathrm{IV}}\right.$ and/or $\left.\mathrm{Pd}^{\mathrm{III}}\right)$ have been employed in catalyzing C-C coupling reactions ${ }^{9}$, very few $\mathrm{C}-\mathrm{C}$ bond formation reactions have been induced by aerobic oxidation of $\mathrm{Pd}^{\mathrm{II}}$ precursors (leading to formation of experimentally detectable $\mathrm{Pd}^{\mathrm{III}}$ or $\left.\mathrm{Pd}^{\mathrm{IV}}\right) .{ }^{10}$ The proposed catalytic cycle with ethane release includes the challenging steps in Scheme $1 \mathrm{~A}$, where transmetalation (step ii) requires a strong oxidant to enable formation of high-valent Pd species. The reductive elimination from dimethyl $\mathrm{Pd}^{\mathrm{II}}$ is slow ${ }^{11}$, hence oxidation to high-valent Pd species are necessary to promote this step to yield ethane. Very few examples of ligands have been reported to facilitate the reactions between $\mathrm{O}_{2}$ and $\mathrm{Pd}^{\mathrm{II}} \mathrm{Me},{ }^{12}$ which also limit the development of aerobic oxidation for the transmetalation step.

Scheme 2. Proposed mechanism for aerobic oxidatively induced reductive elimination of ethane from the $\mathrm{Pd}^{\mathrm{II}}$ dimethyl complex showing possible coordination modes of the ligand L. In the text we used shorthand notations $\mathbf{N}_{\mathbf{2}}$ (for $\kappa^{2}-\mathrm{L}$ ), $\mathbf{N}_{\mathbf{3}}$ (for $\kappa^{3}-\mathrm{L}$ ), and $\mathbf{N}_{\mathbf{4}}$ (for $\left.\mathrm{K}^{4}-\mathrm{L}\right)$. 


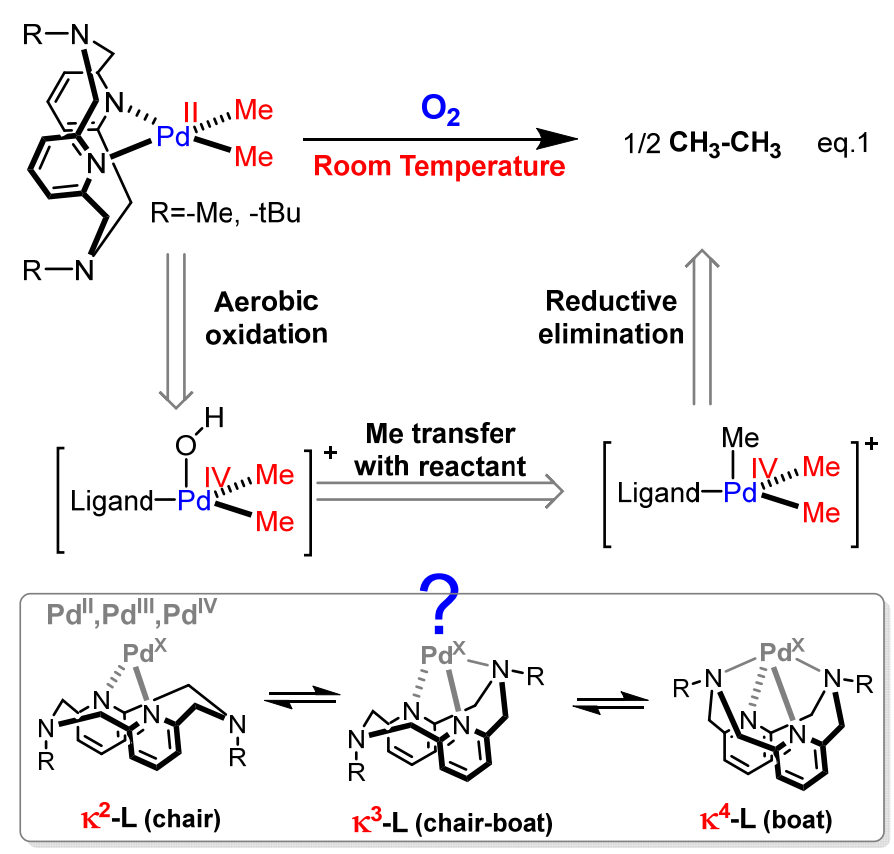

Recently, Mirica and his coworkers reported successful steps in the aerobic oxidative catalysis of methane to ethane with a palladium catalyst featuring a new tetradentate ligand (Scheme 2 , eq 1$)^{13}$. In the catalytic cycle, after the $\mathrm{C}-\mathrm{H}$ bond activation that forms $\mathrm{L}-\mathrm{Pd}^{\mathrm{II}}(\mathrm{Me})_{2}$, oxidation of this complex with molecular oxygen leads to the formation of ethane at room temperature. The authors presented a tentative mechanism for which they have identified many of the intermediates or provided spectroscopic evidence of them. In their mechanism ${ }^{13}$, the initial L-Pd ${ }^{\mathrm{II}}(\mathrm{Me})_{2}$ complex is oxidized by $\mathrm{O}_{2}$ to form a [Pd $\left.\mathrm{Pd}_{-} \mathrm{O}-\mathrm{O}\right]$ complex, whose existence was supported by EPR of DMPO adduct. The peroxide bond cleavage process leads to the $\left[\mathrm{Pd}^{\mathrm{IV}}-\mathrm{OH}\right]^{+}$complex, which is the key intermediate for Me group transfer. Possible $\left[\mathrm{Pd}^{\mathrm{III}}\right]$ complexes had also been proposed to generate tri-methyl $\left[\mathrm{Pd}^{\mathrm{IV}}\right]^{+}$, which was proven to be the precursor for reductive elimination to liberate ethane. Such a facile reaction is unprecedented, and these tetradentate ligands or their analogues have been applied to other interesting reactions by high-valent metals. ${ }^{14}$ Therefore, understanding the mechanism in detail would be useful in order to control and improve such aerobic reaction under mild condition. Unveiling the role of ligand flexibility may suggest other ways to promote oxidation reactions employing mild oxidants. 
Although tremendous effort was expended and much was achieved in the mechanistic study by Mirica's group ${ }^{13}$, several critical issues remain unclear. (1) The crossover experiments imply that the Pd ${ }^{\mathrm{III}}$ complex exhibits low reactivity compare to initial $\mathrm{Pd}^{\mathrm{II}}$ complex, a conclusion which seems discordant with the status of $\mathrm{Pd}^{\mathrm{III}}$ complexes in the tentative mechanism; (2) The reaction is unlikely to be controlled by a non-metal-based radical mechanism, but how does a Me group transfer via a possible metal radical of the $\mathrm{Pd}^{\mathrm{III}}$ complex? What is the state of the Me group during such process, cation, radical, or anion? (3) The experimental studies during the solvent optimization ${ }^{13 b}$ indicate that the reaction rates are accelerated by increasing the concentration of $\mathrm{H}_{2} \mathrm{O}$ in the mixed solvent, $\mathrm{H}_{2} \mathrm{O} / \mathrm{CH}_{3} \mathrm{CN}$, but the role of $\mathrm{H}_{2} \mathrm{O}$ in this reaction is obscure. (4) Recently, Mirica's group proved that the conformational flexibility of the tetradentate ligand is essential for the stabilization of the $\mathrm{Pd}^{\mathrm{III}}$ complex with low oxidation potential ${ }^{15}$. Hence, it is intriguing to investigate how this conformational flexibility affects the entire reaction.

In this paper, we use density functional theory (DFT) calculations to examine the mechanistic issues mentioned above and to gain insight into aerobic oxidative coupling by high-valent Pd. This study provides a route to understand the reliability of these calculations through comparisons with experimental observations. ${ }^{16}$

\section{RESULTS AND DISCUSSION}

\section{a. The ligand's flexibility and its role in key intermediate complexes}

Initial calculations were performed to investigate the ligand flexibility alone and in key intermediates that had been detected experimentally, dimethyl $\mathrm{Pd}^{\mathrm{II}}$, dimethyl $\mathrm{Pd}^{\mathrm{III}}$, and trimethyl $\mathrm{Pd}^{\mathrm{IV}}$. The calculated structures and energies for three stable coordination modes corresponding to three conformations, namely $\kappa^{2}-\mathrm{L}$ (chair), $\kappa^{3}-\mathrm{L}$ (chair-boat) and $\kappa^{4}-\mathrm{L}$ (boat), are shown in Figure 1 (see SI for more $\mathrm{Pd}^{(\mathrm{IV})}$ complexes on ligand flexibility and flipping). The short notation: $\mathbf{N}_{2}$ for $\kappa^{2}-\mathrm{L}, \mathbf{N}_{3}$ for $\kappa^{3}-\mathrm{L}$, and $\mathbf{N}_{\mathbf{4}}$ for $\kappa^{4}-\mathrm{L}$ (Scheme 2) reflects the number of ligand $\mathrm{N}$ atoms coordinated to the metal, except for $\mathrm{Pd}^{\mathrm{IV}}{ }_{-} \mathrm{N}_{4}$, 
where the fourth $\mathrm{N}$ cannot coordinate to Pd because the axial coordination site is occupied by $\mathrm{Me}$ and $\mathrm{OH}$ in $\mathrm{Pd}^{\mathrm{IV}} \mathrm{Me}_{3}-\mathrm{L}$ and $\mathrm{Pd}^{\mathrm{IV}} \mathrm{Me}_{2}(\mathrm{OH})-\mathrm{L}$, respectively.
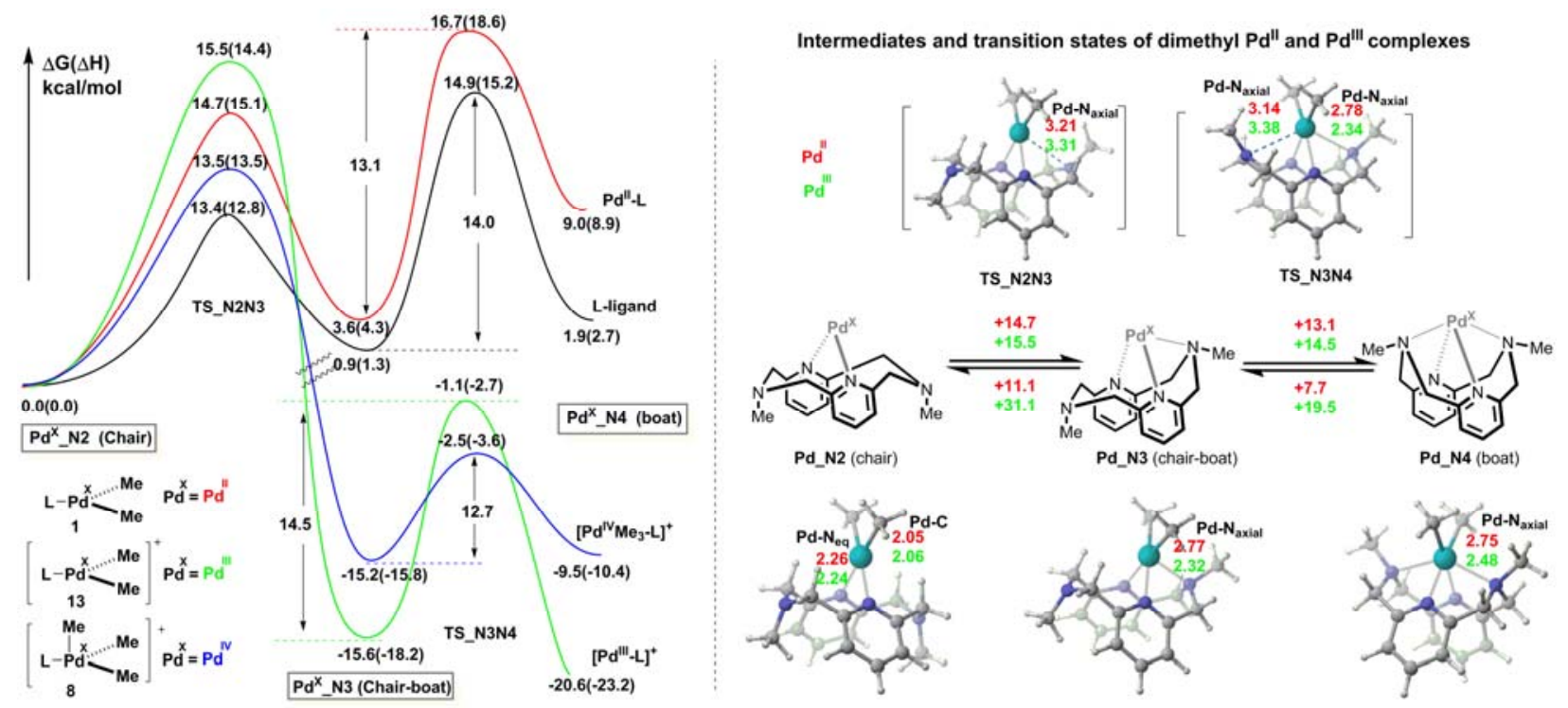

Figure 1. Energy profiles of ligand conformations and coordination modes in various complexes (left panel); and related structures and energies of dimethyl $\mathrm{Pd}^{\mathrm{II}}$ and $\mathrm{Pd}^{\mathrm{III}}$ complexes (right panel). Free ligand ${ }^{\mathrm{Me}} \mathbf{L}$ (L-ligand, black line); ${ }^{\mathrm{Me}} \mathrm{LPd}^{\mathrm{II}} \mathrm{Me}_{2}$ complex ( $\mathrm{Pd}^{\mathrm{II}}-$ $\mathrm{L}$, red line); [ $\left.{ }^{\mathrm{Me}} \mathrm{LPd}^{\mathrm{III}} \mathrm{Me}_{2}\right]^{+}\left(\mathrm{Pd}^{\mathrm{III}}-\mathrm{L} \text {, green line); [ }{ }^{\mathrm{Me}} \mathrm{LPd}^{\mathrm{IV}} \mathrm{Me}_{3}\right]^{+}\left(\mathrm{Pd}^{\mathrm{IV}} \mathrm{Me}_{3}-\mathrm{L}\right.$, blue line); bond lengths shown in $\AA$ and energy shown in $\mathrm{kcal} / \mathrm{mol}$.

Calculations on ligand itself show very small decrease in stability from $\mathbf{N 2}$ (chair), to $\mathbf{N}_{3}$ (chair-boat) and to $\mathbf{N}_{4}$ (boat) conformations with conversion barriers $<15 \mathrm{kcal} / \mathrm{mol}$ (Figure 1, black line), such barriers provide facile transformations at room temperature. The trend was similar for the dimethyl Pd ${ }^{\mathrm{II}}$ complexes with the Pd ${ }^{\mathrm{II}} \_\mathbf{N} 2$ conformation as the most stable, but with a much larger decrease in stability for the $\mathbf{P d}^{\mathrm{II}} \mathbf{N}_{4}$ conformation and a modest increase in the conversion barriers (Figure 1, red line). Due to fully occupied $d_{\mathrm{z} 2}$ orbital of $\mathrm{Pd}^{\mathrm{II}}$, the $\mathrm{Pd}$ to $\mathrm{N}_{\text {axial }}$ distances in $\mathbf{P d}^{\mathrm{II}}{ }_{-} \mathbf{N}_{3}$ and $\mathbf{P d}^{\mathrm{II}}{ }_{-} \mathbf{N}_{4}$ complexes are quite long about $2.7 \AA$. This weak, slightly repulsive interaction is responsible for the decreasing stability trend. Since Pd ${ }^{I I I}$ and $\mathrm{Pd}^{\text {IV }}$ have half empty and empty $d_{z 2}$ orbital, respectively, additional axial coordination is favored here. In $\mathbf{P d}^{\mathrm{III}} \mathrm{N}_{3}$ the Pd- $\mathrm{N}_{\text {axial }}$ bond shortens to $2.3 \AA$ and this complex is $19.2 \mathrm{kcal} / \mathrm{mol}$ more stable (relatively) than the $\mathbf{P d}^{\mathrm{II}} \mathrm{N}_{3}$ complex. While the $\mathbf{P d}^{\mathrm{III}}{ }_{-} \mathbf{N}_{4}$ is significantly more stable 
than the $\mathbf{P d}{ }^{\mathrm{III}}{ }_{-} \mathbf{N}_{3}$, the $\mathbf{P d}^{\mathrm{IV}}{ }_{-} \mathbf{N}_{4}$ is somewhat less stable than the $\mathbf{P d}^{\mathrm{IV}}{ }_{-} \mathbf{N}_{3}$ from the steric crowding of the third Me group. The stabilization of the $\mathrm{N}_{3}$ conformations for both $\mathrm{Pd}^{\mathrm{III}}$ and $\mathrm{Pd}^{\mathrm{IV}}$ complexes inhibits transformation from $\mathrm{N}_{3}$ to $\mathrm{N}_{2}$ (backward barrier $>28$ $\mathrm{kcal} / \mathrm{mol}$ ), while the barriers for transformation between $\mathrm{N}_{3}$ and $\mathrm{N}_{4}$ are much lower, especially for trimethyl $\mathrm{Pd}^{\mathrm{IV}}$ complex with the sterics involved.

\section{b. Mechanism for Aerobic Oxidation of ( $\left.{ }^{\mathrm{Me}} \mathrm{L}\right) \mathrm{Pd}{ }^{\mathrm{II}}$ complex to high-valent Pd}

Despite the importance of $\mathrm{O}_{2}$ activation, there are very few computational studies on aerobic oxidation of Pd catalysts, most of which operate through $\mathrm{Pd}^{\circ} / \mathrm{Pd}^{\mathrm{II}}$ cycles $^{17}$, while $\mathrm{Pd}^{\mathrm{II}} / \mathrm{Pd}^{\mathrm{IV}}$ cycles are usually more unfavorable. ${ }^{1 \mathrm{~b}}$ Recently, Stahl and co-workers reported that the diazafluorene ligand promoted a variety of diverse coordination modes for ligated $\mathrm{Pd}^{\mathrm{II}}$ complexes during aerobic oxidation reactions, implying the important contribution of flexible coordination geometries. ${ }^{18}$ Mirica and co-workers ${ }^{13}$ also found that the flexibility of their tetradentate ligand played key roles in their $\mathrm{Pd}^{\mathrm{II}}$ aerobic oxidations. In addition, they examined the nature of the reaction of $\mathrm{O}_{2}$ with their ${ }^{\mathrm{Me}} \mathrm{LPd}^{\mathrm{II}} \mathrm{Me}_{2}$ complex and reported the formation of a $\left[\mathrm{Pd}^{\mathrm{III}}-\mathrm{O}-\mathrm{O}\right]$ complex, whose DMPO adduct was observed by EPR.

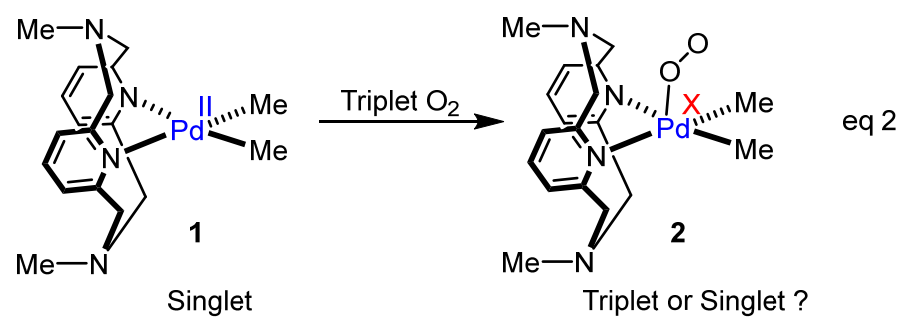

This computational study, to unravel the mechanism of the Pd catalyst's aerobic oxidation and the role of ligand flexibility in the mechanism, begins with an examination of the complex's reaction with $\mathrm{O}_{2}$. The interaction of singlet $\mathrm{Pd}^{\mathrm{II}}-\mathrm{N} 2$ complex with triplet$\mathrm{O}_{2}$ could result in either singlet or triplet state complex, 2 (eq. 2). Note that singlet could be $\mathrm{Pd}^{\mathrm{II}}-\mathrm{N}_{2}-\mathrm{O}_{2}$ or $\mathrm{Pd}^{\mathrm{IV}}-\mathrm{N}_{2}-\mathrm{O}_{2}{ }^{2-}$, while the triplet would be $\mathrm{Pd}^{\mathrm{III}}-\mathrm{N}_{2}-\mathrm{O}_{2}{ }_{2}^{-}$. In our DFT calculations, the singlet complex 2 was obtained without any constrains, by forming a terminally coordinated complex, with a Pd...O bond of $2.29 \AA$ A. The energies of closed- 
shell singlet, as well as the single point energies of triplet and open-shell singlet states, at the optimized singlet structure along the $\mathrm{Pd}-\mathrm{O}$ reaction coordinate distance, are shown in Figure 2. The single point energies of triplet and open-shell singlet states are 17.3 $\mathrm{kcal} / \mathrm{mol}$ and $11.4 \mathrm{kcal} / \mathrm{mol}$ more stable than closed-shell singlet state, respectively. Interestingly, the triplet complex 2 favors dissociation of $\mathrm{O}_{2}$; because of this rather weak interaction between $\mathrm{Pd}^{\mathrm{II}}$ and $\mathrm{O}_{2}$, a fully optimized triplet state has a Pd...O distance of 4.01 Å. Various DFT functionals and coordination modes (e.g. $\mathrm{O}_{2}$ side coordination) of $\mathrm{Pd}^{\mathrm{II}}-\mathrm{N}_{2}$ have been tested to better evaluate the relative energies of spin states and structures (See SI). All the calculations indicate that the unstable $\mathrm{Pd}^{\mathrm{II}}-\mathrm{N}_{2}-\mathrm{O}_{2}$ triplet state is the lowest in energy. Thus, the question arises, how can triplet $\mathrm{O}_{2}$ approach and interact with $\mathrm{Pd}^{\mathrm{II}}$ to form a complex that is stable enough to be trapped by DMPO.

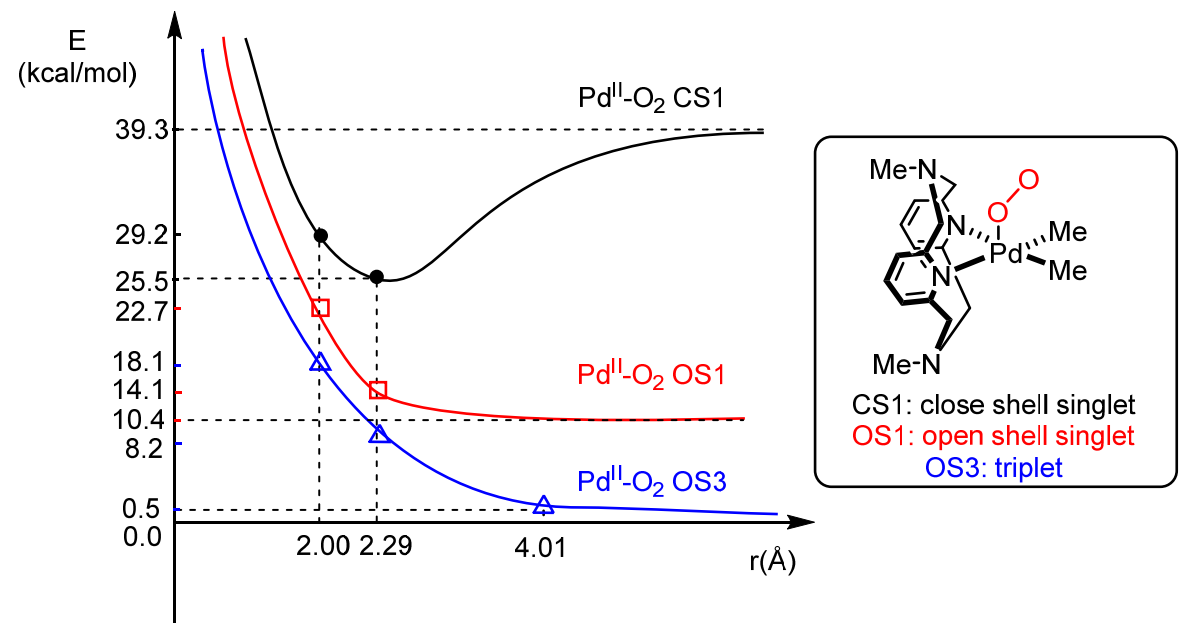

Figure 2. Electronic energy as function of Pd-O distances of different spin states of $\mathbf{P d}^{\mathrm{II}}$ N2- $\mathrm{O}_{2}$ with basis set superposition error (BSSE) corrections.

The lack of driving force to form a $\mathrm{Pd}-\mathrm{O}_{2}$ triplet complex in our calculations led us to calculate ${ }^{\mathrm{Me}} \mathbf{L P d}-\mathrm{O}_{2}-\mathrm{DMPO}$ that had been observed as ${ }^{\mathrm{Me}} \mathbf{L P d} \mathrm{dII}_{-} \mathrm{O}_{2}{ }^{-}$adduct by EPR spectra in Mirica group ${ }^{13}$. We obtained stable triplet states with reasonable Pd-O bond distances of 2.28 $\AA$ and 2.26 $\AA$ in 3-N2 and 3-N3, respectively (Scheme 3). The triplet states are more stable than the singlet states, in agreement with experimental observation of the ${ }^{\mathrm{Me}} \mathrm{L}-$ $\mathrm{Pd}^{\mathrm{III}}-\mathrm{O}_{2}$-DMPO• adduct. Thus, introducing dimethyl pyridine $\mathrm{N}$-oxide (DMPO), a commonly used spin trap for O-centered radicals, is important to stabilize the triplet 
state of the Pd- $\mathrm{O}_{2}$ complex. However, it is still obscure whether the actual ${ }^{\mathrm{Me}} \mathrm{L}-\mathrm{Pd}-\mathrm{O}_{2}$ triplet complex is formed in this aerobic reaction without DMPO. A rational explanation should be that some effects in the reaction itself stabilized the triplet $\mathrm{Pd}-\mathrm{O}_{2}$ adduct inhibiting the $\mathrm{O}_{2}$ dissociation long enough for further reactions to occur.

Scheme 3. Relative energies of ${ }^{\mathrm{Me}} \mathrm{LPd}^{\mathrm{II}}-\mathrm{O}_{2}-\mathrm{DMPO}$ adduct. DMPO combined with $\mathrm{O}_{2}$ dissociate from Pd center. $\Delta \mathrm{E}_{(\mathrm{S})}$ : relative energies of singlet states, $\Delta \mathrm{E}_{(\mathrm{T})}$ : relative energies of triplet states. The distances of Pd-O, O-O and Pd- $\mathrm{N}_{\mathrm{ax}}$ are depicted in the structures. All units of energies and distances throughout our paper are shown in $\mathrm{kcal} / \mathrm{mol}$ and $\AA$, respectively.

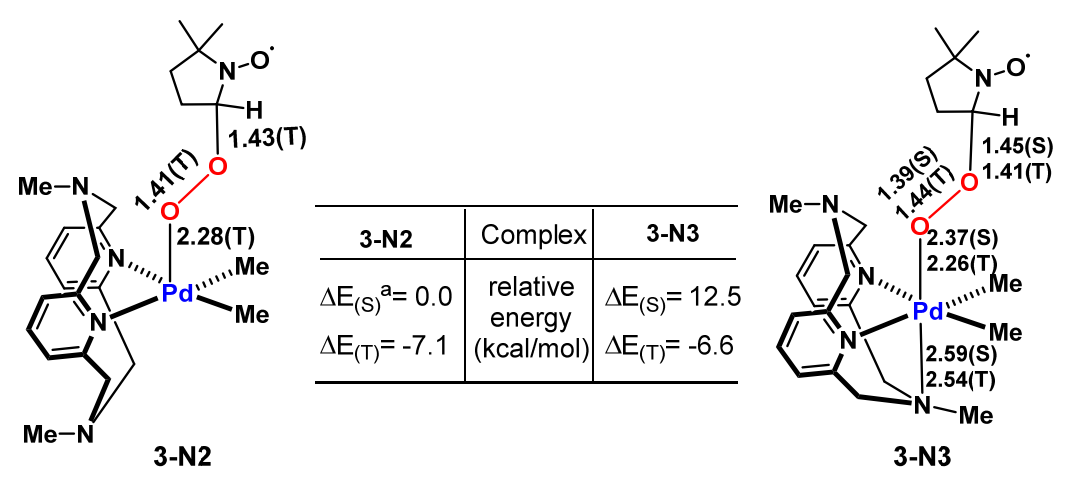

According to Mirica's experimental observations, the reaction was realized when a solution of reactant, dimethyl ${ }^{\mathrm{Me}} \mathrm{L}-\mathrm{Pd}^{\mathrm{II}}$ complex, $\mathbf{1}$, is exposed to $\mathrm{O}_{2}$ or air in the presence of protic solvents (like $\mathrm{H}_{2} \mathrm{O}, \mathrm{MeOH}$ ). Presence of protic solvents provides a potential clue to understand the mystery of a triplet $\mathrm{Pd}-\mathrm{O}_{2}$ complex. To examine the effects of such solvents, the calculated structures were fully optimized in the SMD solvent model with additional explicit protons and solvent molecule(s), such as $\mathrm{H}^{+}, \mathrm{H}_{2} \mathrm{O}, \mathrm{H}_{3} \mathrm{O}^{+},\left(\mathrm{H}_{2} \mathrm{O}\right)_{2}$ and $\left(\mathrm{H}_{2} \mathrm{O}\right)_{3}$. The data show that $\mathrm{Pd}-\mathrm{N}_{3}-\mathrm{O}_{2}$ triplet complex is stabilized by $\mathrm{H}_{2} \mathrm{O}$ molecules (Figure 3 and Figures in SI). The Pd-O bond distances is $3.10 \AA$ in 2_N3, while it is significantly shorter, $2.55 \AA$, in $\mathbf{2}_{-} \mathbf{N}_{3} \_\left(\mathbf{H}_{\mathbf{2}} \mathbf{O}\right)_{3}$. Simultaneously, the spin density increases from 0.137 to 0.462 , while energy difference between the singlet and triplet states decreases, from $9.4 \mathrm{kcal} / \mathrm{mol}$ in $\mathbf{2}_{-} \mathrm{N}_{3}$ to $0.6 \mathrm{kcal} / \mathrm{mol}$ in $\mathbf{2}_{-} \mathbf{N}_{3} \_\left(\mathbf{H}_{\mathbf{2}} \mathrm{O}\right)_{3}$ (Figure $3 \mathrm{~A}$ ). However, explicit $\mathrm{H}_{2} \mathrm{O}$ did not stabilize the $\mathrm{Pd}-\mathrm{N}_{2}-\mathrm{O}_{2}$ triplet complex, as the data on the Pd-O bond distances of $\mathbf{2} \_\mathbf{N} 2$ and $\mathbf{2}_{-} \mathbf{N}_{2}\left(\mathbf{H}_{\mathbf{2}} \mathbf{O}\right)_{3}$ show (Figure ${ }_{3} \mathrm{~B}$ and ${ }_{3} \mathrm{C}$ ). 
(A)

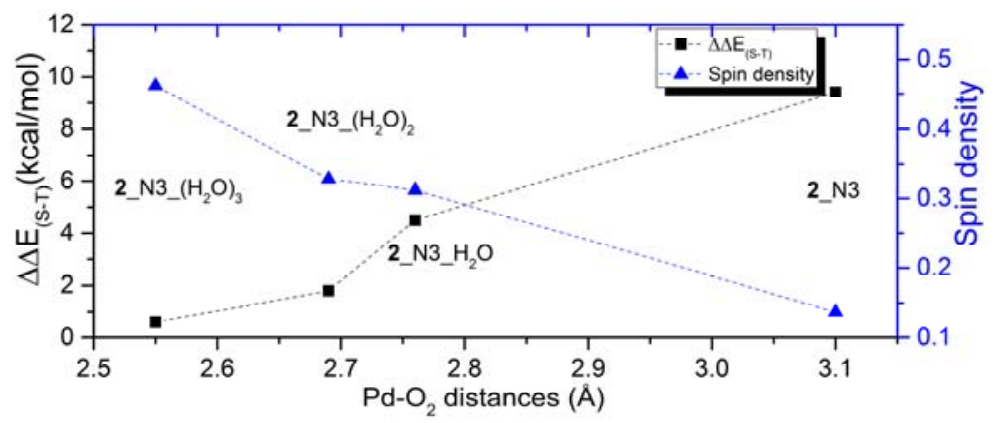

(B)
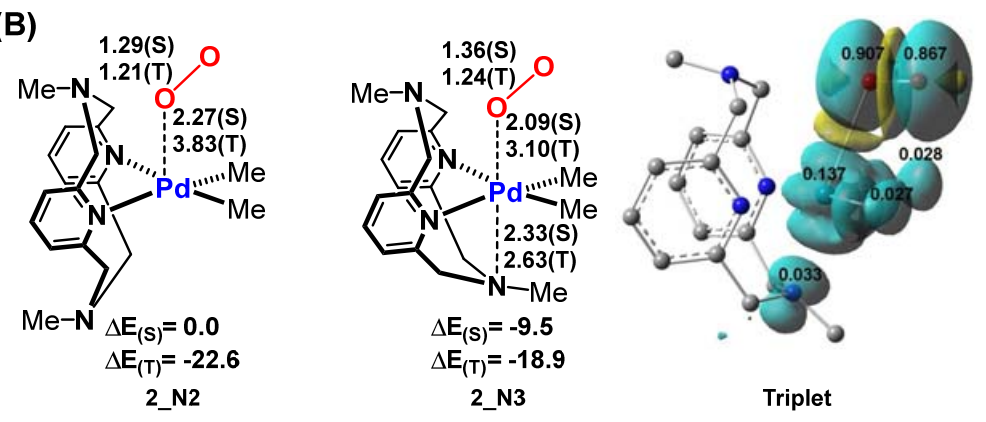

(C)
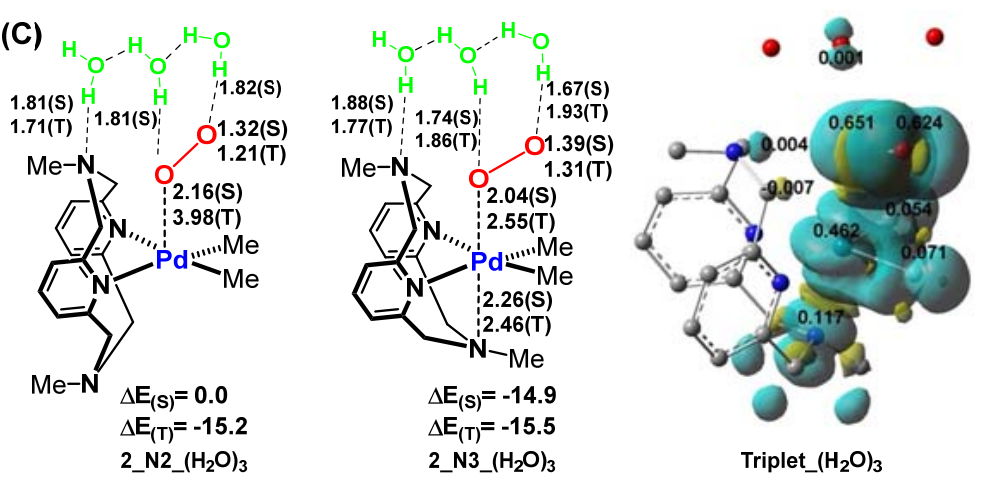

Figure 3. Explicit solvent models of ${ }^{\mathrm{Me}} \mathrm{LPd}^{\mathrm{II}}-\mathrm{O}_{2}$ complexes 2 with two $\mathrm{N}\left(\mathbf{N}_{2}\right)$ and three $\mathrm{N}$ (N3) coordinated to $\mathrm{Pd}$. (A) the trend of $\Delta \mathrm{E}_{(\mathrm{S}-\mathrm{T})}$ and spin density on $\mathrm{Pd}$ with $\mathrm{Pd}-\mathrm{O}_{2}$ distances in testing complex 2, $\Delta \Delta \mathrm{E}_{(\mathrm{S}-\mathrm{T})}=\Delta \mathrm{E}_{(\mathrm{S})}-\Delta \mathrm{E}_{(\mathrm{T})}$; (B) $\mathbf{N}_{2}$ and $\mathbf{N}_{3}$ structures and spin density of complex 2 without $\mathrm{H}_{2} \mathrm{O}$; (C) $\mathrm{N}_{2}$ and $\mathrm{N}_{3}$ structures and spin density of complex 2 with three $\mathrm{H}_{2} \mathrm{O}$ molecules.

In order to form a triplet complex with reasonably strong Pd-O bonds, two key factors are needed: (1) axial $\mathrm{N}$ coordination ( $\mathrm{N}_{3}$ structure) and (2) explicit solvent involvement. First, 2_N2_ $\left(\mathbf{H}_{2} \mathbf{O}\right)_{3}$ without axial $\mathrm{N}$ coordination will dissociate $\mathrm{O}_{2}$ from the low energy triplet complex with a long Pd-O distance of $3.98 \AA$ (Figure $3 \mathrm{C}$ ). Second, 2_N3 without 
$\mathrm{H}_{2} \mathrm{O}$ forms only a weak interaction between $\mathrm{Pd}$ and $\mathrm{O}_{2}$ with a Pd-O distance of $3.10 \AA$ (Figure ${ }_{3} \mathrm{~B}$ ). However, when both key factors are involved as in $\mathbf{2}_{-} \mathbf{N}_{\mathbf{3}}\left(\mathbf{H}_{\mathbf{2}} \mathbf{O}\right)_{3}$, the $\mathrm{Pd}-\mathrm{O}$ bond distance is significantly shorter, $2.55 \AA$ and the complex is stabilized. Similar results are produced by using explicit $\mathrm{MeOH}$ as a protonic source, and the triplet 2_N3_( $\mathrm{MeOH})_{3}$ complex shows a reasonable Pd-O distance of $2.47 \AA$ and spin density on Pd of 0.493 , see Figure $\mathrm{S}_{7}$.
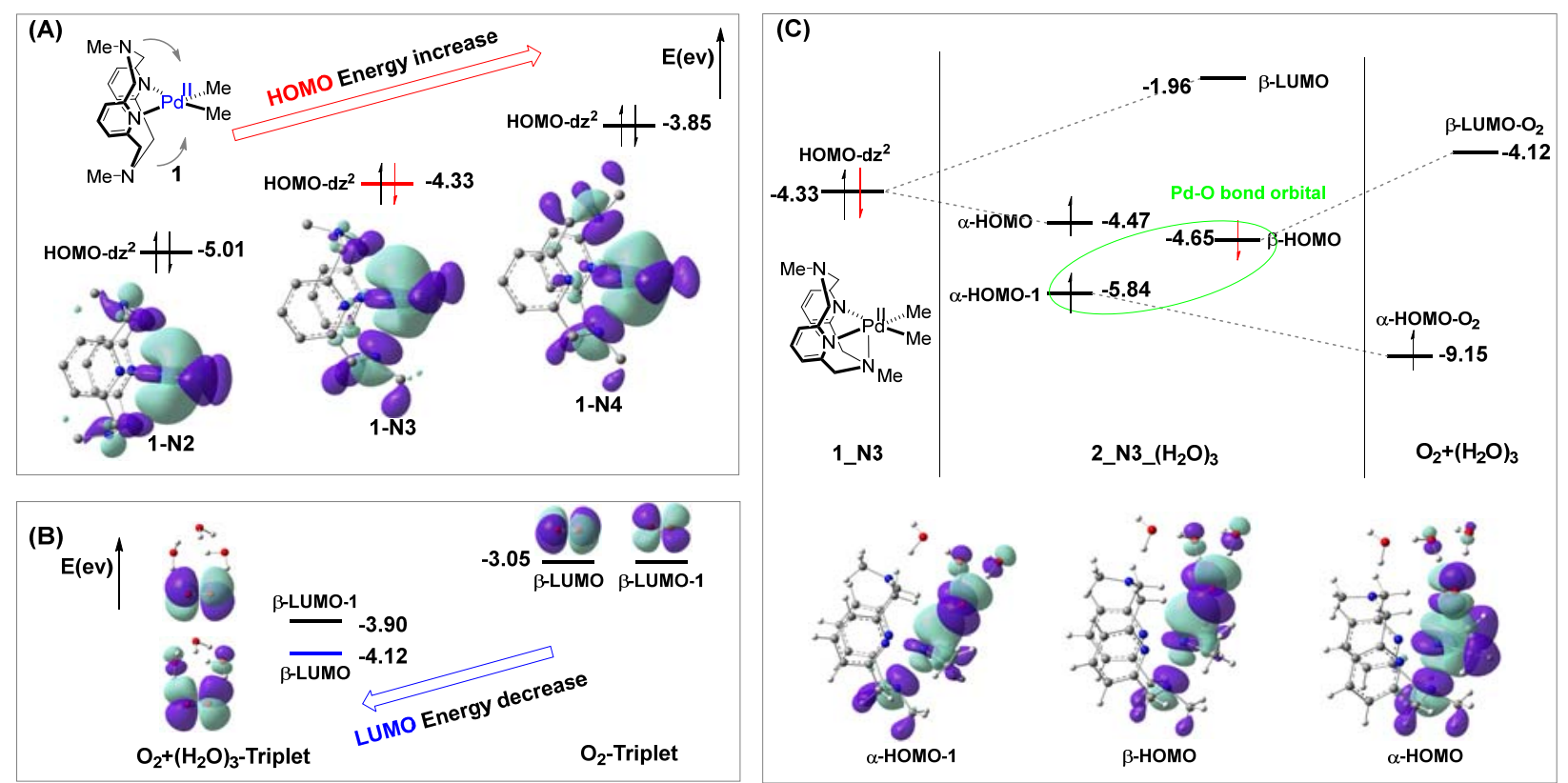

Figure 4. Frontier orbitals of $\left({ }^{\mathrm{Me}} \mathbf{L}\right) \mathrm{Pd}^{\mathrm{II}} \mathrm{Me}_{2}$ complex 1 reacting with triplet $\mathrm{O}_{2}$. (A) Frontier orbitals (HOMOs) of complex 1 with various coordinations; (B) frontier orbitals of triplet $\mathrm{O}_{2}$ with/without $\mathrm{H}_{2} \mathrm{O}$ involved; (C) Molecular diagram for forming the ( $\left.{ }^{\mathrm{Me}} \mathbf{L}\right) \mathrm{Pd}^{\mathrm{II}} \mathrm{Me}_{2^{-}}$ $\mathrm{O}_{2}\left(\mathrm{H}_{2} \mathrm{O}\right)_{3}$ triplet complex $\left(\mathbf{2} \_\mathrm{N}_{3}\right)$.

To rationalize and understand how these two significant factors, axial $\mathrm{N}$ coordination and an explicit solvent $\mathrm{H}_{2} \mathrm{O}$, work together, the frontier orbitals of ${ }^{\mathrm{Me}} \mathbf{L P d}{ }^{\mathrm{II}}$ and $\mathrm{O}_{2}$ were examined (Figure 4). The energies of HOMOs in ${ }^{\mathrm{Me}} \mathbf{L P d}^{\mathrm{II}}$ are highly depend on the axial coordination of $\mathrm{N}$ ligand because the $\mathrm{d}_{\mathrm{z}}{ }^{2}$ character of the complex's HOMO make it sensitive to changes along the axial directions. Coordination of the first axial $\mathrm{N}$ increases the HOMO's energy by $0.68 \mathrm{eV}$, while coordination of the second increases its energy by 
an additional $0.48 \mathrm{eV}$. These energy increases can be ascribed to the electronic repulsion between the lone pair of the axial $\mathrm{N}(\mathrm{s})$ and the $\mathrm{d}_{\mathrm{z}}{ }^{2} \mathrm{HOMO}$ on $\mathrm{Pd}$. The coordination of second axial $\mathrm{N}$ in $\mathbf{2} \_\mathrm{N}_{4}$ will full occupy the available position and will block $\mathrm{O}_{2}$ access; therefore 2_N4 will inhibit the aerobic reaction. The $\beta$-LUMOs of $\mathrm{O}_{2}$ are the antibonding orbitals $(\pi *)$ which may accept electrons from the Pd complex's HOMOs (Figure 4). Due to the relatively high-energy gap in these frontier orbitals, $\mathbf{2}_{-} \mathbf{N}_{3}$ has only a weak interaction between $\mathrm{Pd}$ and $\mathrm{O}_{2}$ reflected by spin density locating on Pd of 0.137 (Figure $\left.{ }_{3} \mathrm{~B}\right)$. Introducing explicit water molecules $\left(\mathrm{H}_{2} \mathrm{O}\right)_{3}$ in the model decreases the $\mathrm{O}_{2} \beta$ LUMO's energy from $-3.05 \mathrm{eV}$ to $-4.12 \mathrm{eV}$ and leads to a more favorable energy gap (Figure $\left.{ }_{4} \mathrm{~B}\right)$. Also, the spin density on Pd and axial N increases to a total of 0.579 , more reflective of $\mathrm{Pd}^{\mathrm{III}}-\mathrm{O}_{2}^{-}$in $\mathbf{2}_{-} \mathrm{N}_{3}-\left(\mathrm{H}_{2} \mathrm{O}\right)_{3}$ (Figure ${ }_{3} \mathrm{C}$ ). A diagram of the frontier orbitals in Figure ${ }_{4} \mathrm{C}$ illustrates the nature of bond formation in triplet $\mathbf{2}_{-} \mathbf{N}_{3}\left(\mathrm{H}_{2} \mathrm{O}\right)_{3}$, where $\alpha-\mathrm{HOMO}-1$ and $\beta$ LUMO were paired to form Pd-O bonding orbital of complex $2_{-} \mathbf{N}_{3}\left(\mathbf{H}_{2} \mathbf{O}\right)_{3}$, which is seen in the orbital contours The remaining two single electrons are in Pd-O anti-bonding ( $\alpha-$ HOMO, hence $\left.\mathrm{Pd}^{\mathrm{III}}\right)$ and an O-O anti-bonding orbital $\left(\alpha-\mathrm{HOMO}-2\right.$, hence $\left.\mathrm{O}_{2}{ }^{-}\right)$that confirms 2_N $\mathbf{N}_{3}\left(\mathrm{H}_{2} \mathrm{O}\right)_{3}$ as a triplet state ${ }^{\mathrm{Me}} \mathrm{LPd}^{\mathrm{III}} \mathrm{Me}_{2}-\mathrm{O}_{2}{ }^{-}$. Thus, both axial coordination of the third $\mathrm{N}$ and explicit solvent are necessary to form ${ }^{\mathrm{Me}} \mathrm{LPd}^{\mathrm{III}} \mathrm{Me}_{2}-\mathrm{O}_{2}{ }^{-}$, protonic solvents are particularly good at this stabilization, hence the importance of $\mathrm{H}_{2} \mathrm{O}$ or $\mathrm{MeOH}$ in this reaction.

\section{c. Peroxide oxidation of complex with spin crossover and $\mathrm{O}-\mathrm{O}$ bond breaking}

The ESI-MS spectra imply complexes 3 and 7 (eq. 3) as intermediates in the reaction mechanism ${ }^{13}$, however, the transformation of triplet complex 2 to singlet 3 and finally to singlet 7 it remains unclear. There are possible spin crossovers from 2 to 3 (Figure 5 ) and O-O bond breaking from 3 reacting with 1 to form 7 as shown in Figure 6. 


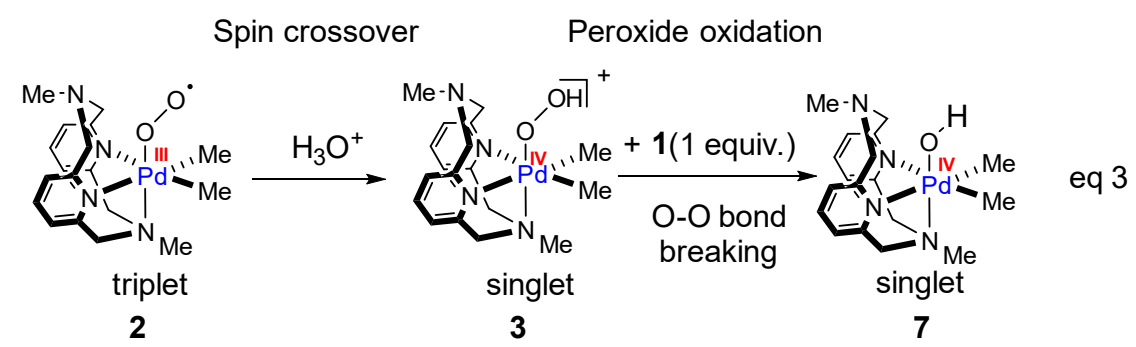

As illustrated above, explicit solvent interactions are essential to stabilizing the triplet complex 2_N3 and strengthening the $\mathrm{Pd}-\mathrm{O}$ bond and preventing the complex's dissociation. As shown in Figure 5 (and Figure SI), these solvent interactions also stabilize the singlet state even more effectively, finally bringing the singlet and triplet state of the 2_N3 $\mathrm{O}_{2}$ complex to nearly the same energy. As explicit $\mathrm{H}_{2} \mathrm{O}$ molecules are added, the barrier to spin crossover drops in electronic energy from $10.0 \mathrm{kcal} / \mathrm{mol}$ in 2_N3 to 2.2 $\mathrm{kcal} / \mathrm{mol}$ in 2_N3_ $\left(\mathbf{H}_{2} \mathbf{O}\right)_{3}$ and $\mathrm{Pd}-\mathrm{O}$ bond lengths at spin crossover point elongates. Further inspection of the $\mathbf{2}_{-} \mathbf{N}_{3} \mathbf{H}_{-}\left(\mathbf{H}_{2} \mathbf{O}\right)_{3}$ structures (Figure ${ }_{3} \mathrm{C}$ ) shows that the hydrogen bonds between $\mathrm{O}_{2}$ and $\mathrm{H}_{2} \mathrm{O}$ in the complex are stronger for the singlet than for the triplet, indicating quite efficient hydrogen bond formation in the singlet but not in the triplet. Moreover, the hydrogen bond to the terminal O $(1.67 \AA)$ is stronger than that to the central O (1.74 $\AA$ ) in the singlet, in contrast to the triplet state with $1.93 \AA$ to the terminal and $1.86 \AA$ to the central $\mathrm{O}$. Therefore, introduction of $\mathrm{H}_{3} \mathrm{O}^{+}$shows significantly stronger stabilization for the singlet state (see SI).

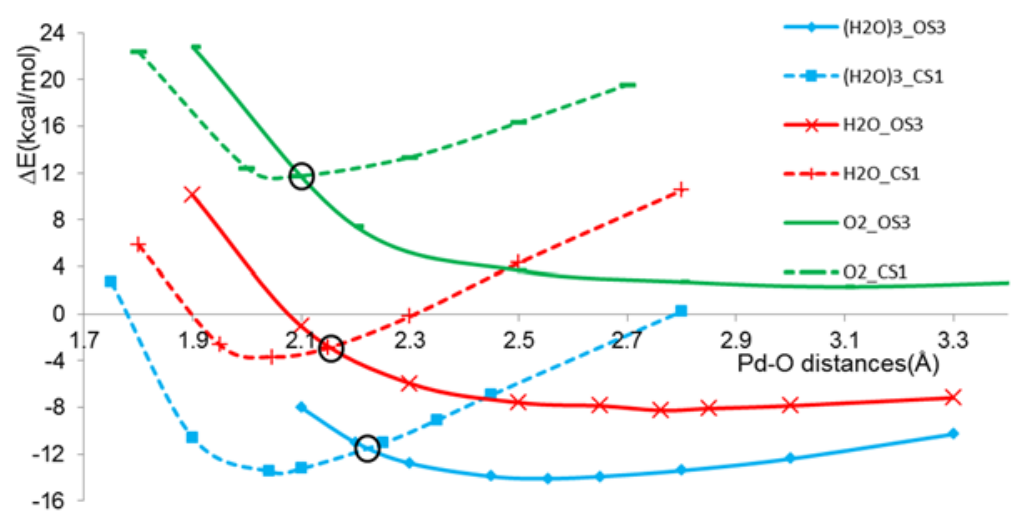




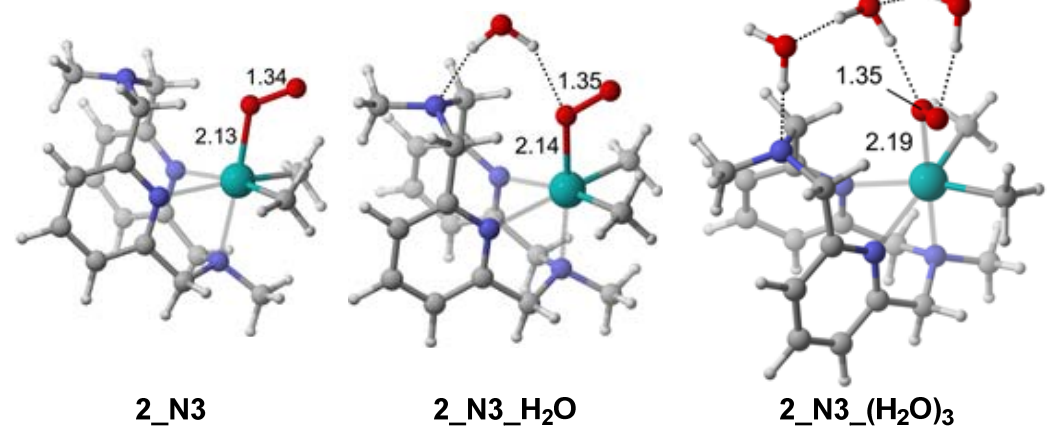

Figure 5. Energy profile for the oxygenation of ${ }^{\mathrm{Me}} \mathbf{L ~ P d}^{\mathrm{II}} \mathrm{Me}_{2} \mathrm{~N}_{3}$ to form the complexes 2_N3_ $\left(\mathbf{H}_{2} \mathrm{O}\right)_{\mathbf{x}}$ involving explicit $\mathrm{H}_{2} \mathrm{O}$. Dash lines show the singlet energy surfaces $\left(\mathrm{CS}_{1}\right)$, solid lines show the triplet energy surfaces $\left(\mathrm{OS}_{3}\right)$. Calculated structures of the spincrossover point between $\mathrm{S}=1$ and $\mathrm{S}=0$ are shown in lower panel.

The calculated free-energy profile of peroxide oxidation process involves two complex species as shown in Figure 6. The profile shows that the process of $\mathrm{O}-\mathrm{O}$ bond breaking is more than $60 \mathrm{kcal} / \mathrm{mol}$ exergonic with an activation barrier of $18.0 \mathrm{kcal} / \mathrm{mol}$. The optimized transition state ( $\mathbf{T S}_{5}$ ) appears to be an early transition state, reflected by Pd-O distance of $2.81 \AA$ and $\mathrm{O}-\mathrm{O}$ bond of $1.57 \AA$. In this process the Pd ${ }^{\mathrm{IV}}$ complex 3 smoothly oxidizes the reactant $\mathrm{Pd}^{\mathrm{II}}$ complex 1 to two $\mathrm{Pd}^{\mathrm{IV}}$ complexes 7 that are the key intermediate for intermolecular Me transfer leading to the tri-methyl $\mathrm{Pd}^{\mathrm{IV}}$.

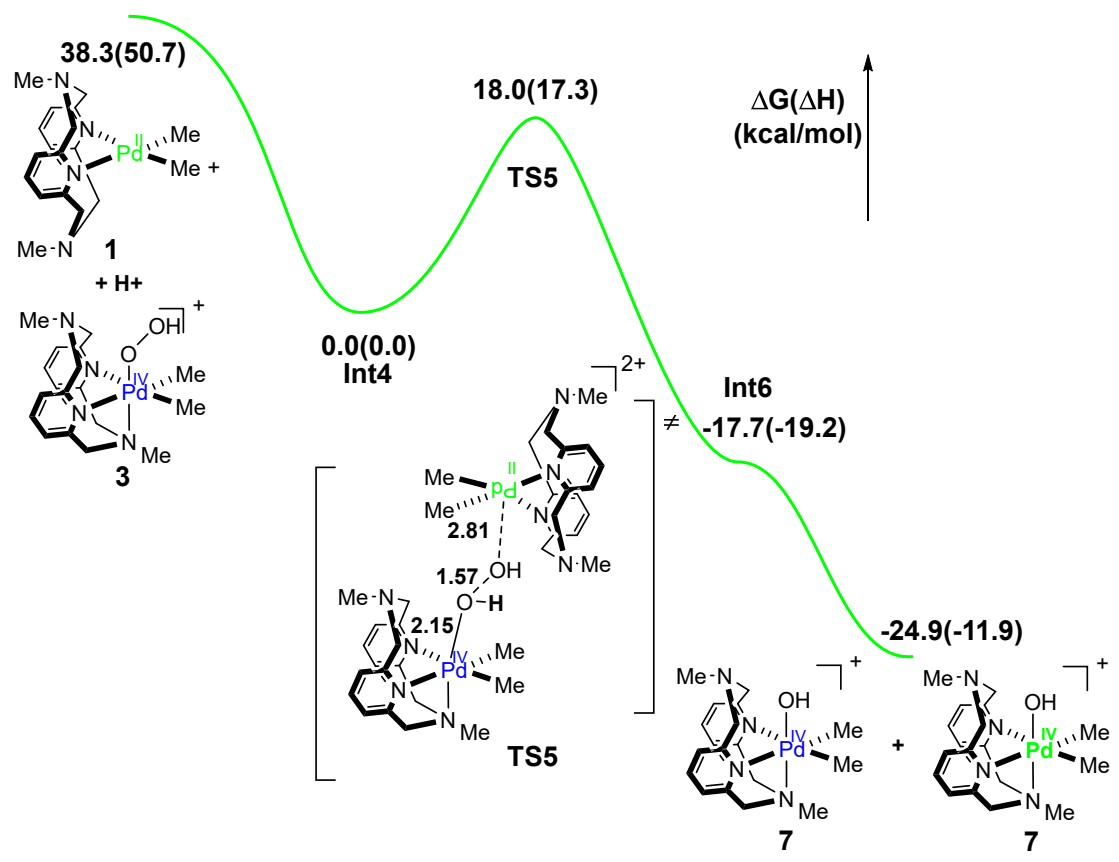


Figure 6. Energy profile of peroxide O-O breaking process, bond distance shown in Å.

\section{d. Mechanisms of intermolecular Me transfer to form ${ }^{\mathrm{Me}} \mathrm{LPd}^{\mathrm{IV}} \mathrm{Me}_{3}$}

Scheme 4. Three proposed mechanism for Me transfer

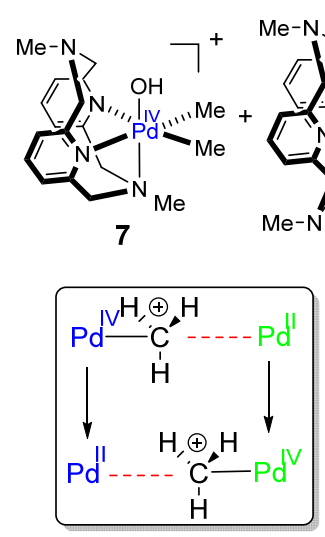

Me cation

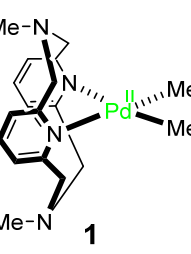

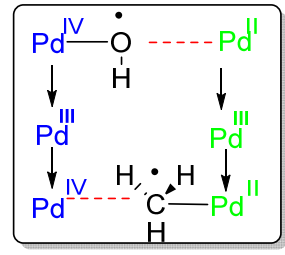

Me radical

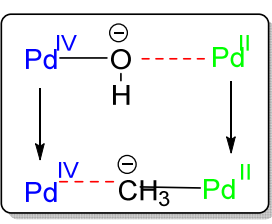

Me anion

Direct reductive elimination of ethane from dimethyl $\mathrm{Pd}^{\mathrm{II}}$ is slow ${ }^{\mathrm{Il}}$, however, highvalent $\mathrm{Pd}^{\mathrm{IV}}$ species promote this step to yield ethane with the assistance of bidentate ${ }^{19}$ and tridentate ligands ${ }^{12 c}$. In Mirica's reaction, the $\left[{ }^{\mathrm{Me}} \mathrm{LPd}^{\mathrm{IV}} \mathrm{Me}_{3}\right]^{+}$complex 8 (eq. 4) was experimentally detected and shown to be the key intermediate for the reductive elimination ${ }^{13}$. However, the mechanism of obtaining the trimethyl species $\mathbf{8}$ from species 7 remained unknown. Based on the proposed mechanisms in experimental work, three plausible pathways, with changes of valence states on $\mathrm{Pd}$, are shown in Scheme 4; Me cation, Me radical, and Me anion. Because no vacant coordination sites are available in complex 7, possible mechanisms were proposed to transfer relevant species between complex $\mathbf{7}$ and complex $\mathbf{1 .}$ 


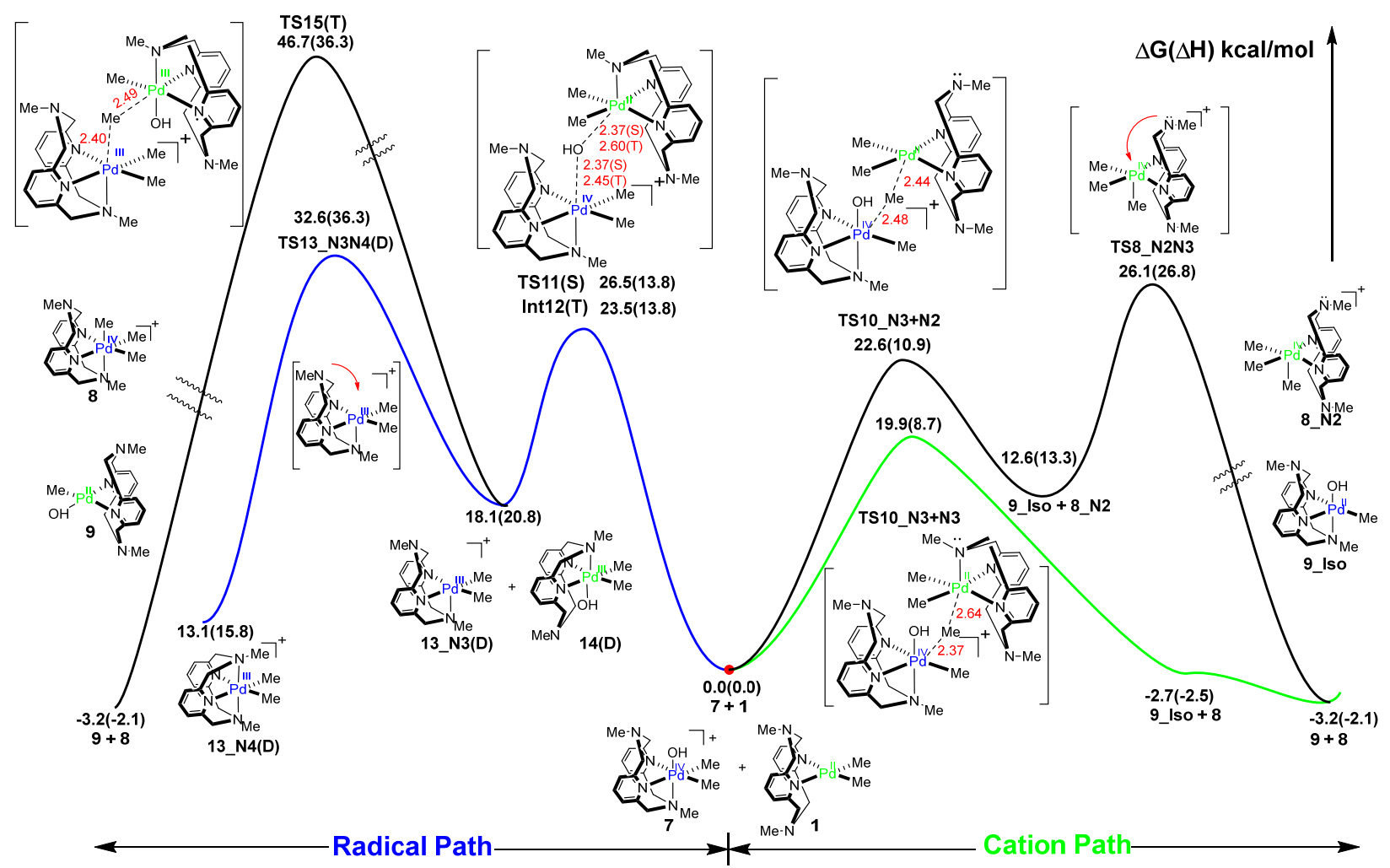

Figure 7. Energy profile of intermolecular Me transfer to form ${ }^{\mathrm{Me}} \mathrm{LPd}^{(\mathrm{IV})} \mathrm{Me}_{3}$, involving possible ligand flexibility of the tetradentate ligand. Most of the structures were optimized in singlet state (S) except for those shown as D (doublet) and T (triplet). Bond distance for transition states shown in $\AA$, energies are in $\mathrm{kcal} / \mathrm{mol}$.

First, the 'Me anion' pathway is ruled out by our initial calculations showing that dissociating $\mathrm{OH}^{-}$from 7 would require rather high activation energy $(45.9 \mathrm{kcal} / \mathrm{mol}$ in free energy with solvent correction), which is impossible at room temperature. The 'Me radical' and 'Me cation', as two competitive pathways, were investigated in detail and their energy profiles are shown in Figure 7. The comparison of two pathways shows that 'Me cation' pathway (green line in Figure 7) is most favorable when complex 1 gains axial coordination of the ligand $\mathbf{L}\left(\mathbf{1}_{-} \mathbf{N}_{3}\right)$ beginning with the transition state. This Me cation transfer crosses a $19.9 \mathrm{kcal} / \mathrm{mol}$ free-energy barrier via a rather early transition state (TS10_N $3+\mathrm{N}_{3}$, with the $\mathrm{Pd}^{\mathrm{IV}}-\mathrm{Me}$ transferring at a distance of $2.37 \AA$ ) and forms a thermodynamically stable intermediate $\left[\mathrm{Pd}^{\mathrm{IV}} \mathrm{Me}_{3}\right]^{+} \mathbf{8}\left(\mathbf{8} \_\mathbf{N}_{2}\right)$. As we discussed before (Scheme 2 and Figure 1 ), the $\mathrm{Pd}^{\mathrm{II}}$ complex $\mathbf{1}$ is able to easily transform between $\kappa^{2}-, \kappa^{3-}$ 
and $\kappa^{4}$ - coordinations, which makes the transition state $\mathbf{T S} \mathbf{1 o}_{\mathbf{1}} \mathrm{N}_{3}+\mathrm{N}_{3}$ easily available. An alternative 'Me cation' transition state (TS1o_N3+N2), in which 1 remains an N2 complex, has a free-energy barrier of $22.6 \mathrm{kcal} / \mathrm{mol}$ with a relatively late TS (with the $\mathrm{Pd}^{\mathrm{IV}}-\mathrm{Me}$ distance of $2.48 \AA$ ). This transition state is followed by transformation of $\mathrm{N}_{2}$ to $\mathrm{N}_{3}$ coordination in trimethyl $\mathrm{Pd}^{\mathrm{IV}}$ species 8 . Because of this latter transformation, the overall barrier is $26.1 \mathrm{kcal} / \mathrm{mol}$, higher than for the case of the earlier ligand conformational change in the $\mathrm{Pd}^{\mathrm{II}}$ complex $1(19.9 \mathrm{kcal} / \mathrm{mol})$. Hence, the pathway with TS1o_N3+N2 is less competitive (Figure 7). A cation pathway for Me transfer has also been suggested for bidentate ligand processes ${ }^{19}$.

In calculations on the 'Me radical' pathway, the $\cdot \mathrm{OH}$ and $\cdot \mathrm{Me}$ radicals are transferred between two Pd (see proposed mechanism in Scheme 4). The Pd ${ }^{\mathrm{III}}$ doublet 13 (Figure 7), as a short-lifetime intermediate, could be observed experimentally by EPR and ESI-MS ${ }^{13}$. The calculations indicated the two-step intermolecular transfer of $\cdot \mathrm{OH}$ and $\cdot$ Me radicals between two Pd complexes; where each step has free-energy barrier over $23.5 \mathrm{kcal} / \mathrm{mol}$ (radical path in Figure 7). The overall barrier of $46.7 \mathrm{kcal} / \mathrm{mol}$ makes this pathway less possible. However, regarding the step of forming $\mathrm{Pd}^{\mathrm{III}}$ doublet complex, the energy barrier for $\mathrm{OH}$ transfer step varies with different functionals and solvent models (i.e. Mo6L/CPCM: $20.1 \mathrm{kcal} / \mathrm{mol}$, see SI for details). Thus, some of the functionals and solvent models suggest that first step of $\cdot \mathrm{OH}$ transfer to form $\mathrm{Pd}^{\mathrm{III}}$ doublet $\mathbf{1} 3$ and $\mathbf{1 4}$ is possible at RT. Moreover, this step is reversible (the barrier in reverse direction is lower) and, in comparison to the 'Me cation' pathway, more favorable to form thermodynamically stable $\mathrm{Pd}^{\mathrm{IV}}$ complex 7 and $\mathrm{Pd}^{\mathrm{II}}$ complex 1. This could rationalize the experimental observation of directly $\mathrm{C}-\mathrm{C}$ formation from $\mathrm{Pd}^{\mathrm{III}}$ complex without $\mathrm{O}_{2}$. One can consider an alternative way to form the $\mathrm{Pd}^{\mathrm{III}}$ doublet 13, by single electron transfer (SET) between $\mathrm{Pd}^{\mathrm{IV}}$ complex 7 and $\mathrm{Pd}^{\mathrm{II}}$ complex 1 (Scheme 5 ); however, this step is thermodynamically unfavorable as shown in eq. 5 of Scheme 5 . However, the Pd ${ }^{\mathrm{III}}$ doublet 13 can be obtained from the fast SET reaction of dimethyl $\mathrm{Pd}^{\mathrm{IV}}$ complex 16 and $\mathrm{Pd}^{\mathrm{II}}$ complex $\mathbf{1}$ in an exergonic way, supporting by analogue complex in the experiment. ${ }^{20}$ Computationally, we cannot find evidence for methyl transfer by a radical pathway; however, $\mathrm{Pd}^{\mathrm{III}}$ species can be formed by 
SET, which is in agreement with experimental data on non-metal-based radical mechanism. ${ }^{13 b}$

Scheme 5. Single electron transfer between $\mathrm{Pd}^{\mathrm{IV}}$ and $\mathrm{Pd}^{\mathrm{II}}$ to form $\mathrm{Pd}^{\mathrm{III}}$

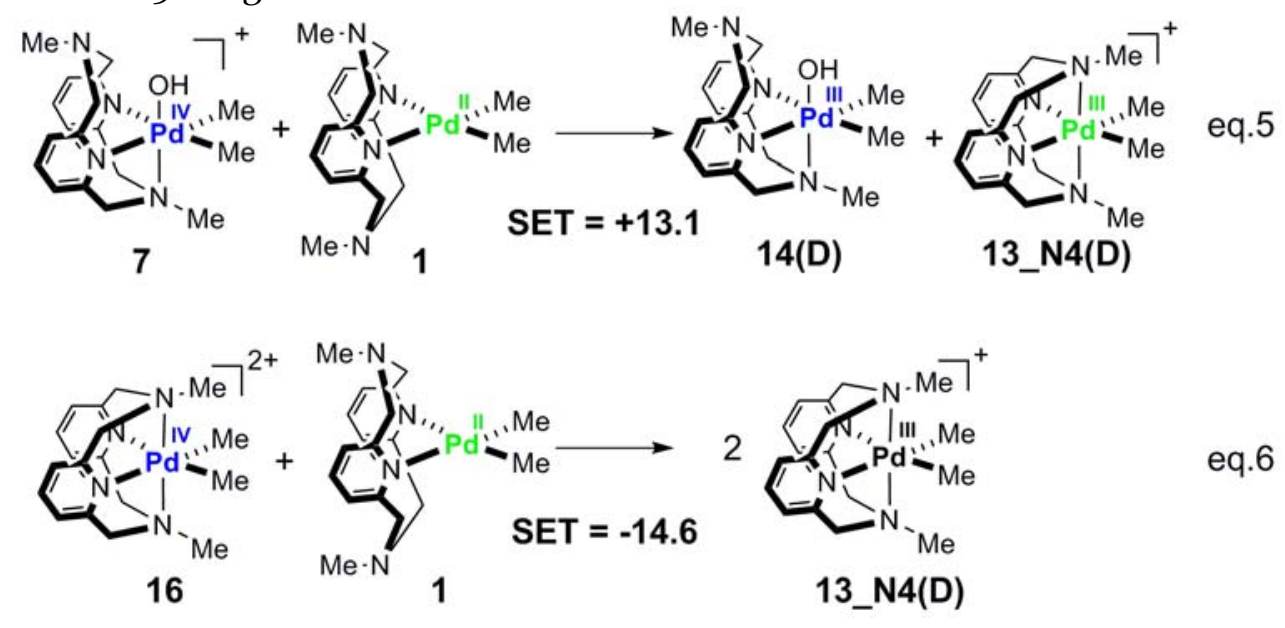

e. Ways for Reductive elimination-the fate of ${ }^{\mathrm{Me}} \mathrm{LPd}^{\mathrm{IV}} \mathrm{Me}_{3}$ complex 8

Three possible ${ }^{\mathrm{Me}} \mathrm{LPd}^{\mathrm{IV}} \mathrm{Me}_{3}$ complexes of $\mathbf{8}$, with ligand coordination modes $\mathbf{8} \_\mathbf{N} \mathbf{2}$, $\mathbf{8} \_\mathbf{N}_{3}$ and $\mathbf{8} \_\mathbf{N}_{4}$ are intermediates connected via two transition states (TS8_N2 $\mathbf{N}_{3}$ and TS8_N3N4) with reasonable energy barriers as shown in Scheme 6. Ligand flipping from 8_N2 to $\mathbf{8} \_N_{3}$ is irreversible $(+13.5 /+28.7 \mathrm{kcal} / \mathrm{mol})$ while transformations between $\mathbf{8} \_\mathbf{N}_{3}$ and $\mathbf{8} \_\mathbf{N}_{4}$ are reversible with low energy barriers of $+12.7 /+7.0$. The calculated $\mathbf{8} \_\mathbf{N}_{3}$ is the most stable isomer, in agreement with the crystal structure of the ${ }^{\mathrm{Me}} \mathrm{LPd}^{\mathrm{IV}} \mathrm{Me}_{3}$ complex ${ }^{13 \mathrm{~b}}$. Each of these three isomers of complex $\mathbf{8}$ can undergo reductive eliminations (RE) via transition states $\mathbf{T S 8} \mathbf{R E}_{-}\left(\mathbf{N}_{2}, \mathbf{N}_{3}, \mathbf{N}_{4}\right)$ to form thermodynamically favorable products Pro8_(N2, N3, N4) (Figure 9). A rather low energy barrier for RE has been located from 8_N2 suggesting that low coordination number of ligand ${ }^{M e} \mathbf{L}$ could benefit the RE mechanism, probably because $\mathrm{Pd}^{\mathrm{IV}}$ in $\mathbf{8} \_\mathbf{N 2}$ is electron deficient. This result is in agreement with the favourable RE in five coordination species found by Goldberg for Ir ${ }^{\mathrm{III}}$ complexes. ${ }^{21}$ On the other hand, RE from $\mathbf{8} \_\mathbf{N 2}$ could be blocked by the high energy barrier of irreversible ligand flipping from $\mathbf{8} \_N_{3}$ to $\mathbf{8} \_N_{2}(28.7 \mathrm{kcal} / \mathrm{mol}$ due to Pd-N bond breaking), which is likely inoperative at RT, indicating the role of the axial coordination 
in RE step in this system. Through our whole mechanism, RE would be the ratedetermining step, while $\mathbf{8} \_\mathbf{N}_{3}$ or $\mathbf{8} \_\mathbf{N}_{\mathbf{4}}$ would be the active species undergoing RE with reasonable and nearly equal energy barriers. Although at RT the calculated barrier is slightly high at $24.4 \mathrm{kcal} / \mathrm{mol}$ different functional produce lower barriers, such as 21.1 $\mathrm{kcal} / \mathrm{mol}$ with $\omega-\mathrm{B} 97 \mathrm{XD}$. Thus, these barriers are in reasonably good agreement with experimental observations of the long-lived intermediate 8 with $t_{1 / 2}$ for elimination of ethane at $68 \mathrm{~min}$ at $\mathrm{RT}$ and 6.7 days at $-20^{\circ} \mathrm{C} .{ }^{13 \mathrm{~b}}$

Scheme 6. Energy barriers of reductive elimination from ${ }^{\mathrm{Me}} \mathrm{LPd}^{\mathrm{IV}} \mathrm{Me}_{3}$ complex $\mathbf{8}$, considering ligand flexibility. Although in $\mathbf{8} \_\mathbf{N}_{4}$ there are four available Ns from the ligand, the fourth $\mathrm{N}$ cannot coordinate to Pd because its axial coordination has been blocked by Me.

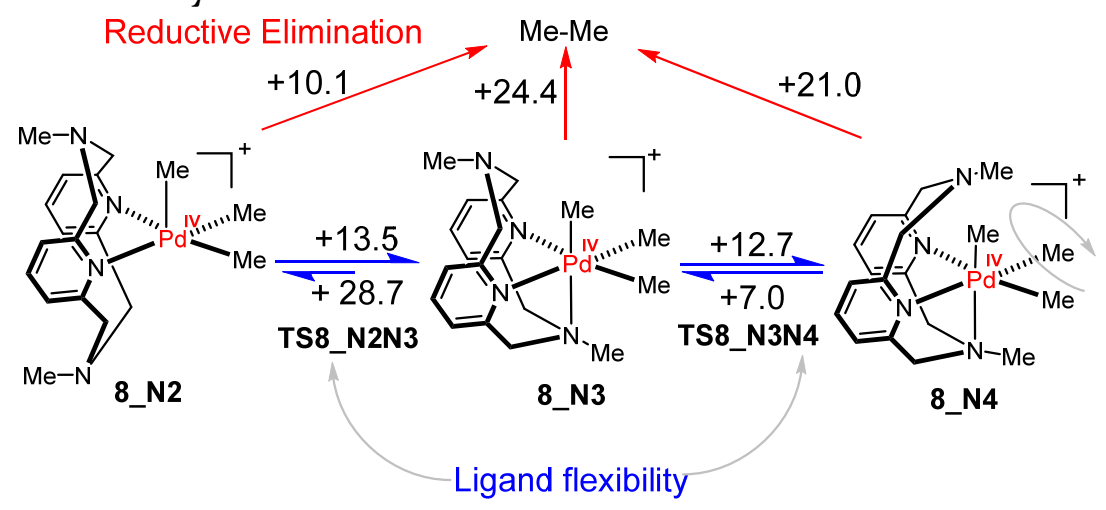




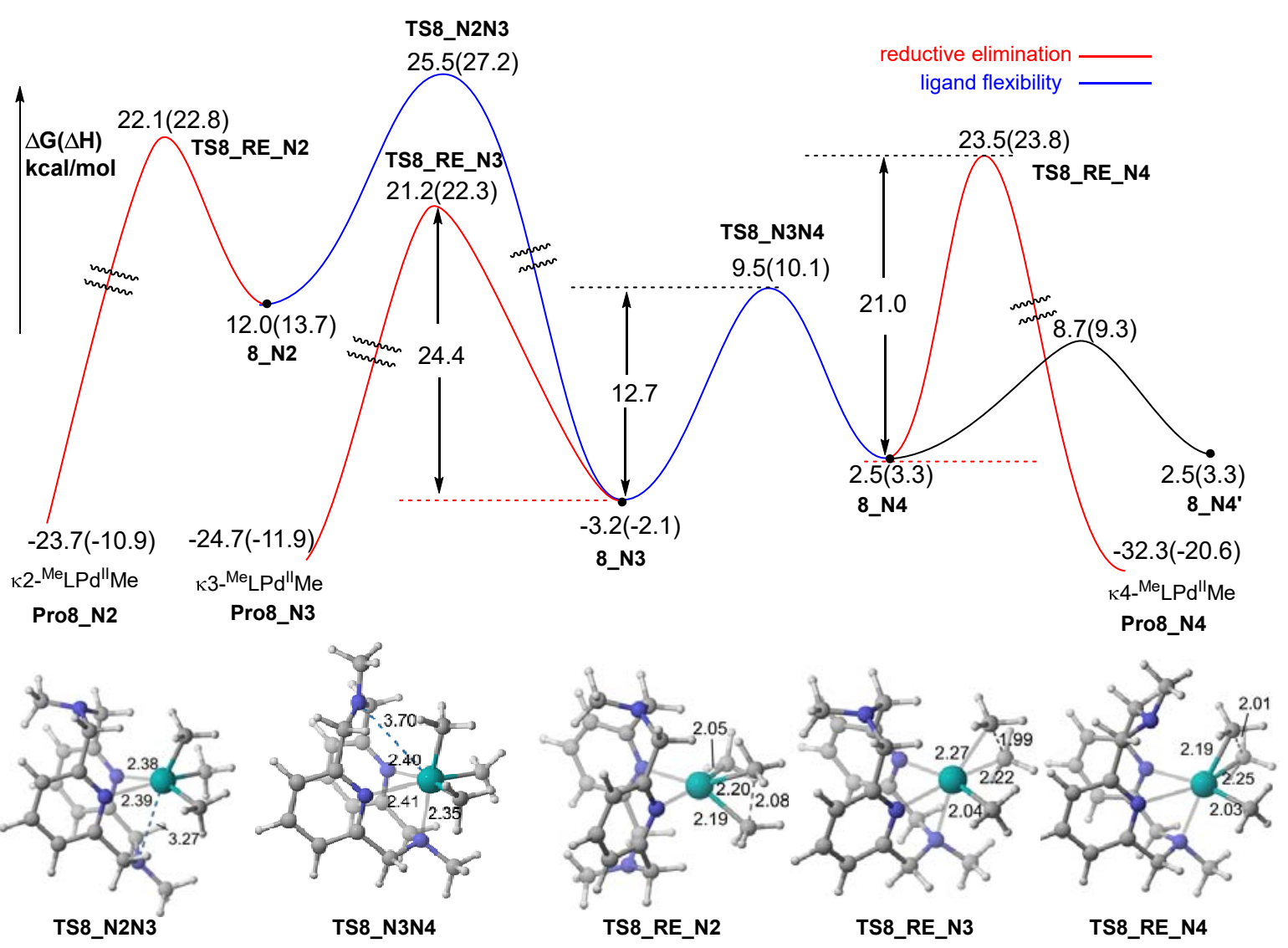

Figure 8. Energy profiles of reductive elimination (red line) combined with ligand flipping (blue line). Rotation of the three Me group is shown in black line. Structures of TSs are shown in lower panel. The "Pro" label is used for precursors of products.

The low rotation barrier $(6.2 \mathrm{kcal} / \mathrm{mol})$ among the three Me group of $\mathbf{8} \_\mathbf{N}_{4}$ lead to the same isomer 8_N4', in which the axial and equatorial Me groups have exchanged. This fluxionality was observed experimentally and plays a role in the distribution of products from isotopically labeled reactants ${ }^{13}$, since in the reductive elimination mechanism axialequatorial pairs are always eliminated. ${ }^{22}$ Theses mechanistic path can be rationalized by looking at the orbitals. During the elimination of two methyl groups, two electrons need to refill an orbital on $\mathrm{Pd}$ bringing it back to $\mathrm{Pd}^{\mathrm{II}}$; refilling in $d \mathrm{z}^{2}$ through an axialequatorial RE is much more favorable than refilling the $d x^{2}-y^{2}$ through an equatorialequatorial RE because the $d \mathrm{z}^{2}$ orbital is more stable than the $d \mathrm{x}^{2}-\mathrm{y}^{2}$ (Scheme 7) . 
Scheme 7. Comparison of axial elimination and equatorial elimination

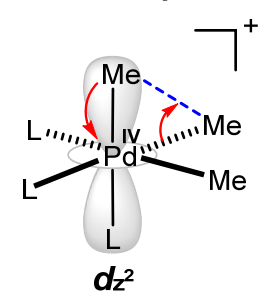

Axial elimination

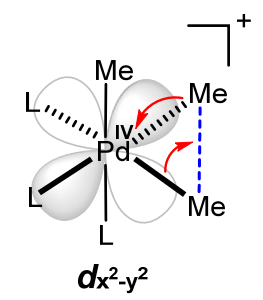

equatorial elimination

Scheme 8. Reductive elimination from intermediates $\mathbf{1}, \mathbf{1 3}$, and 7. The C-C or C-O bond distances and activation energies are shown. ${ }^{\text {aD }}$ ue to the weak coordination of one Pdpyridine (2.89 $\AA$ ) in the transition state. The two Me groups are differentiated as axial and equatorial. Therefore, this RE from 7 is a low-energy axial-equatorial RE consistent with our discussion above. Rotation to place the $\mathrm{OH}$ trans to pyridine to produce 7 ' is not favorable.

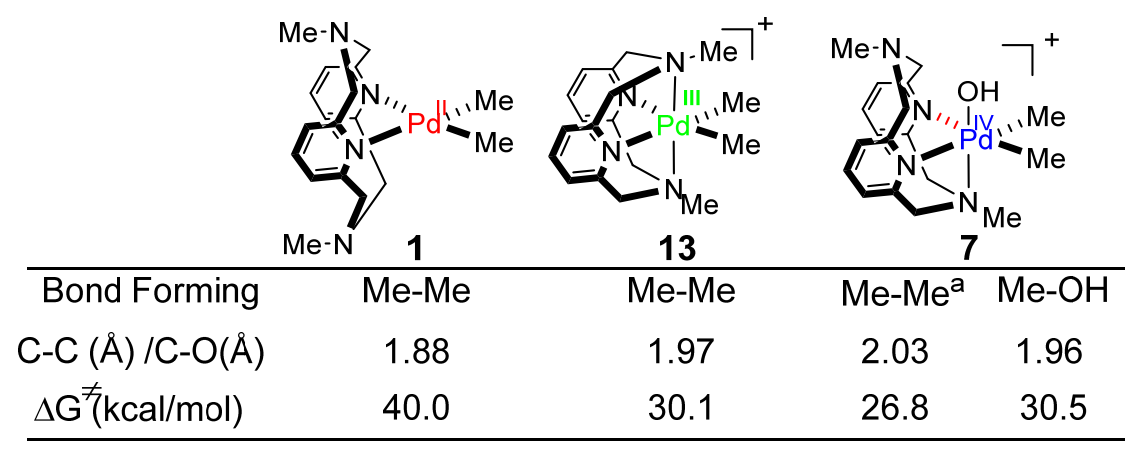

Additional calculations were carried out to evaluate RE from other potential candidates that have been detected in the reaction mechanism (eg. complexes 1, 7 and 13) ${ }^{13}$. As we anticipated, all these intermediates have higher activation energies and would not undergo RE at room temperature (Scheme 8). Thus complex $\mathbf{8}$ is only reasonable intermediate for RE to ethane. Reductive elimination is the fastest for high-valent $\mathrm{Pd}^{\mathrm{IV}}$, the rate increases with increasing oxidation state from $\mathrm{Pd}^{\mathrm{II}}$ to $\mathrm{Pd}^{\mathrm{IV}}$ (Scheme 8 ). The computations on RE of complex 7 indicate that the direct $\mathrm{C}-\mathrm{O}$ bond formation is more difficult than $\mathrm{C}-\mathrm{C}$ bond formation, a result that supports the recent report, by Vedernikov and co-worker, of yielding methanol in strong base. ${ }^{12 c}$ 


\section{CONCLUSION}

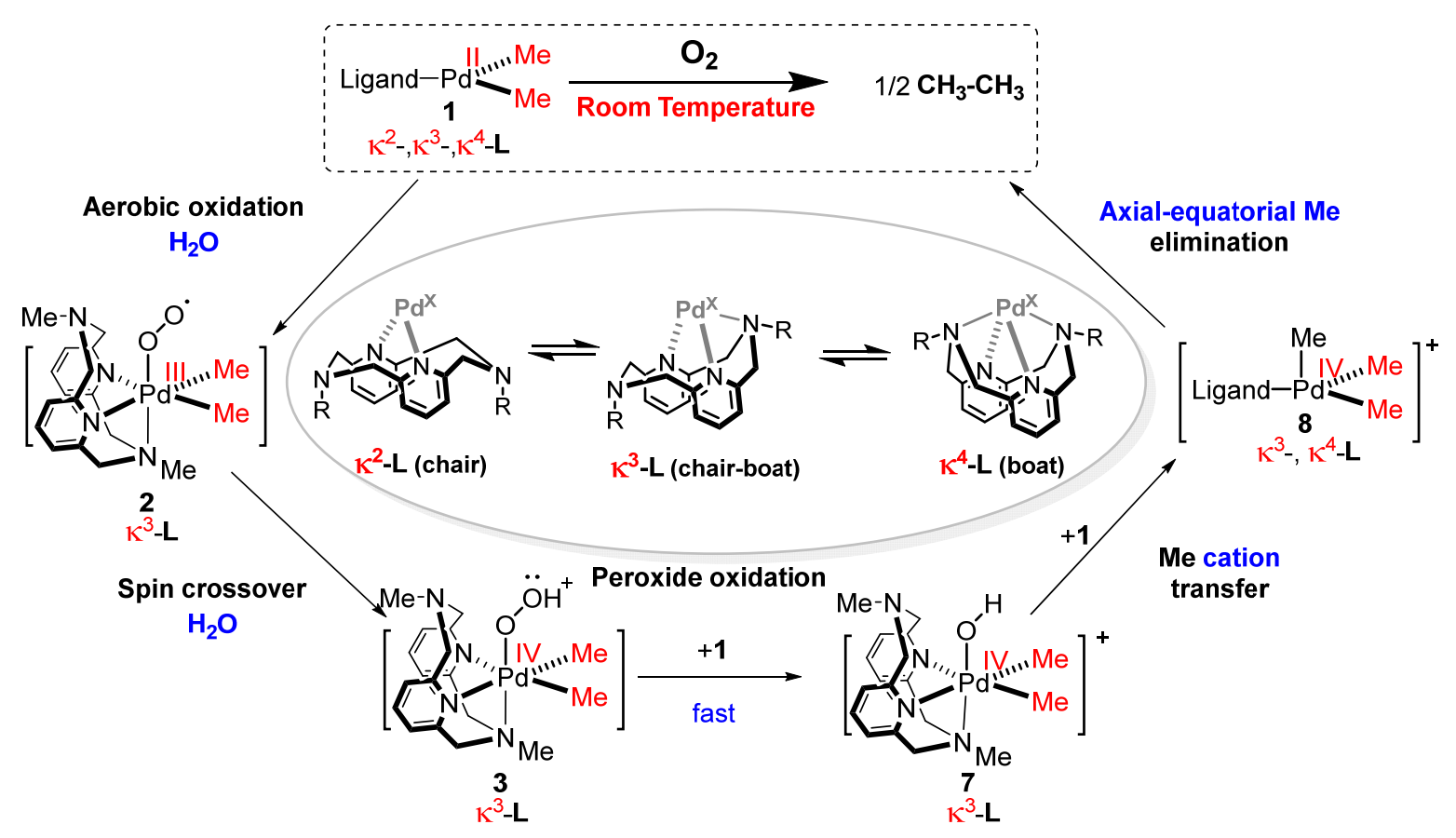

Figure 9. DFT confirmed mechanism of Aerobic Oxidative from $\mathrm{Pd}^{\mathrm{II}}$ dimethyl complex to release ethane under mild condition.

In summary, this work describes the first detailed computational study on aerobic oxidation of tetradentate ligated $\mathrm{Pd}^{\mathrm{II}}$ complex 1 to generate $\mathrm{H}_{3} \mathrm{C}-\mathrm{CH}_{3}$ (Figure 9). The calculated mechanism suggests five key transformations in this reaction: (1) aerobic oxidation of $\mathrm{Pd}^{\mathrm{II}}$ complex 1 to $\mathrm{Pd}^{\mathrm{III}}-\mathrm{O}_{2}{ }^{-}$complex 2 , (2) spin crossover between $\mathrm{Pd}^{\mathrm{III}}$ complex 2 and $\mathrm{Pd}^{\mathrm{IV}}-\mathrm{OOH}$ complex 3, (3) peroxidation of a $\mathrm{Pd}^{\mathrm{II}}$ complex 1 by the $\mathrm{Pd}^{\mathrm{IV}}-$ $\mathrm{OOH}$ complex 3, (4) Me cation transfer from $\mathrm{Pd}^{\mathrm{IV}} \mathrm{Me}_{2} \mathrm{OH}$ complex 7 to $\mathrm{Pd}^{\mathrm{II}}$ complex 1, (5) reductive elimination of $\mathrm{Pd}^{\mathrm{IV}} \mathrm{Me}_{3}$ complex 8. From the computation on this mechanism, we discovered that $\mathrm{H}_{2} \mathrm{O}$ (or other solvents, especially protonic ones) is essential to assist the aerobic oxidation by decreasing $\mathrm{O}_{2}$ LUMO energy and stabilizing $\mathrm{Pd}-\mathrm{O}_{2}$ complex. Me cation transfer was suggested to be the more favorable than radical and anion pathways. For the final reductive elimination step, it is preferred that the axial-equatorial methyl releases ethane from $\mathrm{Pd}^{\mathrm{IV}}$ complex 8. Furthermore, ligand flexibility plays a significant 
role and it is necessary to stabilize the most of intermediates and transition states, although in some case the contribution can be negative for a certain step (eg. reductive elimination prefers five coordination $\kappa^{2}$-species). This flexibility leads to diverse axial coordination modes and provides a constructive clue to design new ligand systems, which would be critical to other chemical reaction such as late-stage $\mathrm{C}-\mathrm{H}$ functionalization. ${ }^{23}$ More studies toward conformational flexibility in chemistry are currently underway.

\section{COMPUTATIONAL DETAILS}

All quantum chemical calculations at the level of the density functional theory (DFT) were carried out with the Gaussiaon o9 Revision D.o1 program package ${ }^{24}$. Molecular geometries were fully optimized by using the dispersion-corrected $\mathrm{B}_{3} \mathrm{LYP}_{\mathrm{P}} \mathrm{D}_{3}{ }^{25}$ functional without any symmetry constraints and broken symmetry approachs were employed for open-shell optimization. The effective core potentials (ECPs) of Hay and Wadt with a triple- $\zeta$ basis set (LANL2TZ) ${ }^{26}$ were used for Pd, and the 6-31G(d, p) basis set was used for $\mathrm{H}, \mathrm{C}, \mathrm{N}$ and $\mathrm{O}\left(\mathrm{BS}_{1}\right)$. The energies were recalculated using a larger basis set $(6-311++\mathrm{G}(\mathrm{d}$, p) basis set for $\mathrm{H}, \mathrm{C}, \mathrm{N}$ and $\mathrm{O}$ ) and triple- $\zeta$ basis set (LANL2TZ) for Pd (BS2) by singlepoint calculations, in implicit solvent treated with the universal solvation SMD model ${ }^{27}$ and polarizable conductor $\mathrm{CPCM}$ model ${ }^{28}$. $\mathrm{MeCN}$ was used as solvent with a dielectric constant value of 35.688 and using UAHF (United Atom Hartree-Fock) radii for the respective atoms (Pd, H, C, N and $\mathrm{O}$ ) in both SMD and CPCM calculations. For the part of $\mathrm{O}_{2}$ coordination to $\mathrm{Pd}$, calculated structures were fully optimized in SMD solvation model using $\mathrm{B}_{3}$ LYP-D3/BS1 to better evaluate $\mathrm{O}_{2}$ behavior in solvent. Basis set superposition error (BSSE) was also applied in this part. The minimum energy crossing points (MECP), here are spin cross point in $\mathrm{Pd}-\mathrm{O}_{2}$ complex, were calculated by structures scanning and the software developed by Harvey group ${ }^{29}$.

All the structures were computed with the complete ligand structure as in the experiment. Additional density functionals such as $\mathrm{B}_{3} \mathrm{LYP}^{30}, \mathrm{Mo6L}^{31}, \mathrm{Mo6}^{32} \omega-\mathrm{B}_{97} \mathrm{XD}^{33}$, TPSS $^{34}$, TPSSh ${ }^{34}$, were applied in selected intermediates and transition states to evaluate the functional influence. All optimized species were verified as either minima or 
transition structures by the presence of zero or a single imaginary vibrational frequency. Free energies were evaluated at $298 \mathrm{~K}$ using harmonic vibrational frequencies. Saddle points were connected to minima in the usual way with intrinsic reaction coordinate (IRC) calculations. The energies given throughout the paper are relative energy values computed with Gaussian 09 at $298 \mathrm{~K}$ and $\mathrm{P}=1 \mathrm{~atm}$. Computed structures are displayed with CYLVIEW35.

\section{ASSOCIATED CONTENT}

\section{Supporting Information.}

Optimized geometries of stationary points involved in energy profiles but not shown in the main text; comparison results for B3LYP, TPSS, TPSSh, Mo6 and Mo6L in optimized $\mathrm{Pd}-\mathrm{O}_{2}$ complex; test possible coordination $\mathrm{Pd}-\mathrm{O}_{2}$ complex; full calculated explicit solvent models of $\mathrm{Pd}-\mathrm{O}_{2}$ complex; scanned energy profiles of spin cross between triplet and singlet $\mathrm{Pd}-\mathrm{O}_{2}$ complex; spin density of $\mathrm{Pd}-\mathrm{O}_{2}$ complex with explicit solvent; comparison results for $\omega_{\mathrm{B}}{ }_{77 \mathrm{XD}} \mathrm{B}_{3} \mathrm{LYP}, \mathrm{B}_{3} \mathrm{LYP}-\mathrm{D}_{3}$ and Mo6L in reaction mechanism; mechanism of ligand flipping in more $\mathrm{Pd}^{\mathrm{IV}}$ species; and the total energies and Cartesian coordinates of the structures involved in this study. This material is available free of charge via the Internet at http://pubs.acs.org

\section{AUTHOR INFORMATION}

\section{Corresponding Authors}

qpeng@nankai.edu.cn; mbhall@tamu.edu

Notes

The authors declare no competing financial interest.

\section{ACKNOWLEDGMENT}

The authors acknowledge financial support of The Welch Foundation (A-0648 to MBH) for initial support of this work. The majority of the work was supported by financial support from the Qatar National Research Fund under NPRP grant 7-297-1-051 to MBH and ENB. The work was completed with the help of National Natural Science Foundation 


\section{REFERENCES}

(1) Clayden, J.; Greeves, N.; Warren, S.; Wothers, P. Organic Chemistry (1st ed.); Oxford University Press. USA. 2001, pp. 460-461.

(2) (a) Dubois, D. L. Inorg. Chem. 2014, 53 , 3935-396o. And reference therein. (b) Theoretical predict catalyst: Fernandez, L. E.; Horvath, S.; Hammes-Schiffer, S. J. Phys. Chem. Lett. 2013, 4, 542-546.(c) Improved catalyst by Structural Dynamics:Cardenas, A. J. P.; Ginovska, B.; Kumar, N.; Hou, J.; Raugei, S.; Helm, M. L.; Appel, A. M.; Bullock, R. M.; O'Hagan, M. Angew. Chem. Int. Ed. 2016, 55, 13509.

(3) (a) Crabtree, R. H. Chem. Rev. 1995, 95, 987. (b) Holmen, A. Catal. Today 2009, 142, 2. (c) Alvarez-Galvan, M. C.; Moto, N.; Ojeda, M.; Rojas, S.; Navarro, R. M.; Fierro, J. L. G. Catal. Today 2011, 171, 15.(d) Hammond, C.; Conrad, S.; Hermans, I. ChemSusChem 2012, 5,1668.

(4) (a) Negishi, E. Handbook of Organopalladium Chemistry for Organic Synthesis; John Wiley \& Sons: Hoboken, NJ, 2002; (b) van Leeuwen, P. W. N. M. Homogeneous Catalysis: Understanding the Art; Kluwer Academic Publishers: Dordrecht, 2004.

(5) (a) Miyaura, N.; Suzuki, A. Chem. Rev. 1995, 95, 2457. (b) Hartwig, J. F. Organotransition Metal Chemistry: From Bonding to Catalysis; University Science Books: Sausalito, 2010.

(6) (a) Stuart, D. R.; Fagnou, K. Science 2007, 316, 1172. (b) Yeung, C. S.; Dong, V. M. Chem. Rev. 2011, 111, 1215.

(7) (a)Liu, C.; Yuan, J.; Gao, M.; Tang, S.; Li, W.; Shi, R.; Lei, A. Chem. Rev. 2015, 115, 12138-12204.(b) Lehman, M. C.; Pahls, D. R.; Meredith, J. M.; Sommer, R. D.; Heinekey, D. M.; Cundari, T. R.; Ison, E. A. J. Am. Chem. Soc. 2015, 137 , 3574-3584.(c) Xiao, D. J.; Gonzalez, M. I.; Darago, L. E.; Vogiatzis, K. D.; Haldoupis, E.; Gagliardi, L.; Long, J. R. J. Am. Chem. Soc. 2016, 138, 7161.

(8) (a) Stahl, S. S. Angew. Chem., Int. Ed. 2004, 43, 3400. (b) Stoltz, B. M. Chem. Lett. 2oo4, 33, 362. (c) Gligorich, K. M.; Sigman, M. S. Chem. Commun. 2009, 3854. (d) Izawa, Y.; Stahl, S. S. Adv. Synth. Catal. 2010, 352, 3223. (e) Campbell, A. N.; Meyer, E. B.; Stahl, S. S. Chem. Commun. 2011, 47, 10257.(f) Campbell, A. N.; Stahl, S. S. Acc. Chem. Res. 2012, 45, 851-863.

(9) (a) Hull, K. L.; Lanni, E. L.; Sanford, M. S. J. Am. Chem. Soc. 20o6, 128, 14047. (b) Canty, A., J. Chem. Soc., Dalton Trans. 2009, 10409. (c) Chen, X.; Engle, K. M.; Wang, D.-H.; Yu, J.-Q. Angew. Chem., Int. Ed. 2oo9, 48, 5094. (d) Daugulis, O.; Do, H.-Q.; Shabashov, D. Acc. Chem. Res. 2009, 42, 1074. (e) Muniz, K. Angew. Chem., Int. Ed. 2009, 48, 9412. (f) Lyons, T. W.; Sanford, M. S. Chem. Rev. 2010, 110, 1147. (g) Sehnal, P.; Taylor, R. J. K.; Fairlamb, I. J. S. Chem. Rev. 2010, 110, 824.(h) Powers, D. C.; Ritter, T. Top. Organomet. Chem. 2011, 35, 129.(g) Topczewski, J. J.; Sanford, M. S. Chem. Sci. 2015, 6 , 70-76.

(10) (a) McAuley, A.; Whitcombe, T. W. Inorg. Chem. 1988, 27, 309o. (b) Chuang, G. J.; Wang, W.; Lee, E.; Ritter, T. J. Am. Chem. Soc. 2011, 133, 1760.

(11) Remy, M. S.; Cundari, T.; Sanford, M. S. Organometallics 2010, 29, 1522.

(12) (a) Boisvert, L.; Denney, M. C.; Hanson, S. K.; Goldberg, K. I. J. Am. Chem. Soc. 20o9, 131, 15802-15814. (b) Petersen, A. R.; Taylor, R. A.; Vicente-Hernandez, I.; Mallender,' P. R.; Olley, H.; White, A. J. P.; Britovsek, G. J. P. J. Am. Chem. Soc. 2014, 136, 14089-14099. (c) Sberegaeva, A. V.; Zavalij, P. Y.; Vedernikov, A. N. J. Am. Chem. Soc. 2016, 138, 1446-1455. 
(13) (a) Khusnutdinova, J. R.; Rath, N. P.; Mirica, L. M, J. Am. Chem. Soc., 2012, 134, 2414-2422.(b) Tang, F.; Zhang, Y.; Rath, N. P.; Mirica, L. M. Organometallics, 2012, 31, 6690-6696;(c) Tang, F.; Qu, F.; Khusnutdinova, J. R.; Rath, N. P.; Mirica, L. M. Dalton Trans., 2012, 41, 14046-14050.

(14) (a) Zheng, B.; Tang, F.; Luo, J.; Schultz, J. W.; Rath, N. P.; Mirica, L. M. J. Am. Chem. Soc., 2014,136, 64996504;(b) Zhou, W.; Schultz, J. W.; Rath, N. P.; Mirica, L. M. M. J. Am. Chem. Soc., 2015, 137, 7604-7607; (c) Zhou, W.; Rath, N. P.; Mirica, L. M. M., Dalton Trans., 2016, 45, 8693-8695; (d) Zhou, W.; Zheng, S.; Schultz, J.; Rath, N. P.; Mirica, L. M. M, . J. Am. Chem. Soc., 2016, 138, 5777-5780.

(15) Khusnutdinova, J. R.; Rath, N. P.; Mirica, L. M. Inorg. Chem. 2014, 53, 13112-13129.

(16) Cheng, G. J.; Zhang, X.; Chung, L. W.; Xu, L.; Wu, Y. D. J. Am. Chem. Soc. 2015, 137, 1706-1725.

(17) (a )Popp, B. V.; Wendlandt, J. E.; Landis, C. R.; Stahl, S. S. Angew. Chemie - Int. Ed. 20o7, 46, 6o1-6o4.(b) Popp, B. V.; Stahl, S. S. Chem. - A Eur. J. 2009, 15, 2915-2922.(c) Dang, Y.; Deng, X.; Guo, J.; Song, C.; Hu, W.; Wang, Z. X. J. Am. Chem. Soc. 2016, 138 , 2712-2723.

(18) White, P. B.; Jaworski, J. N.; Fry, C. G.; Dolinar, B. S.; Guzei, I. A.; Stahl, S. S. J. Am. Chem. Soc. 2016, 138, 4869-4880.

(19) Lotz, M. D.; Remy, M. S.; Lao, D. B.; Ariafard, A.; Yates, B. F.; Canty, A. J.; Mayer, J. M.; Sanford, M. S. J. Am. Chem. Soc. 2014, 136 8237-8242.

(20) Mirica, L. M.; Khusnutdinova, J. R. Coord. Chem. Rev., 2013, 257, 299-314.

(21) Boisvert, L.; Goldberg, K. I. Acc. Chem. Res. 2012, 45 , 899-910.

(22) In our calculation, trying to eliminate two equatorial Me will automatically rotate to one axial and one equatorial Me.

(23) Topczewski, J. J.; Cabrera, P. J.; Saper, N. I.; Sanford, M. S. Nature 2016, 531, 220-224.

(24)Gaussian 09, Revision D.o1, Frisch, M. J.; Trucks, G. W.; Schlegel, H. B.; Scuseria, G. E.; Robb, M. A.; Cheeseman, J. R.; Scalmani, G.; Barone, V.; Mennucci, B.; Petersson, G. A.; Nakatsuji, H.; Caricato, M.; Li, X.; Hratchian, H. P.; Izmaylov, A. F.; Bloino, J.; Zheng, G.; Sonnenberg, J. L.; Hada, M.; Ehara, M.; Toyota, K.; Fukuda, R.; Hasegawa, J.; Ishida, M.; Nakajima, T.; Honda, Y.; Kitao, O.; Nakai, H.; Vreven, T.; Montgomery, J. A., Jr.; Peralta, J. E.; Ogliaro, F.; Bearpark, M.; Heyd, J. J.; Brothers, E.; Kudin, K. N.; Staroverov, V. N.; Kobayashi, R.; Normand, J.; Raghavachari, K.; Rendell, A.; Burant, J. C.; Iyengar, S. S.; Tomasi, J.; Cossi, M.; Rega, N.; Millam, N. J.; Klene, M.; Knox, J. E.; Cross, J. B.; Bakken, V.; Adamo, C.; Jaramillo, J.; Gomperts, R.; Stratmann, R. E.; Yazyev, O.; Austin, A. J.; Cammi, R.; Pomelli, C.; Ochterski, J. W.; Martin, R. L.; Morokuma, K.; Zakrzewski, V. G.; Voth, G. A.; Salvador, P.; Dannenberg, J. J.; Dapprich, S.; Daniels, A. D.; Farkas, Ö.; Foresman, J. B.; Ortiz, J. V.; Cioslowski, J.; Fox, D. J. Gaussian, Inc., Wallingford CT, 2009.

(25) Grimme, S.; Antony, J.; Ehrlich S. and Krieg, H. J. Chem. Phys., 2010, 132, 154104.

(26) (a) Hay, P.J. and Wadt, W.R. J. Chem. Phys. 1985, 82, 299. (b) Roy, L.E.; Hay,P.J. and Martin, R.L. J. Chem. Theory Comput. 2008, 4, 1029.

(27) Marenich, A. V.; Cramer,C. J.; and Truhlar, D. G. J. Phys. Chem. B, 2009, 113, 6378-96 .

(28)Cossi, M.; Rega, N.; Scalmani, G.; and Barone, V. J. Comp. Chem., 2003, 24, 669-81.

(29)Harvey, J.N.; Aschi, M.; Schwarz, H.; Koch, W. Theor. Chem. Acts., 1998, 99, 95.

(30)(a) Becke, A. D. Phys. Rev. 1988, A38, 3098. (b) Becke, A. D. J. Chem. Phys. 1993, 98, 1372. (c) Becke, A. D. J. Chem. Phys. 1993, 98, 5648. (d) Lee, C.; Yang, W.; Parr, R. G. Phys. Rev. 1988, B37, 785.

(31) Zhao, Y.; Truhlar, D. G. J. Chem. Phys. 2006, 125, 194101: 1.

(32) Zhao, Y.; Truhlar, D. G. Theor. Chem. Acc. 20o8, 120, 215.

(33) Chai, J.-D.; and Head-Gordon, M.; Phys. Chem. Chem. Phys. 20o8, 10, 6615.

(34)Tao, J. M; Perdew,J. P.; Staroverov, V. N.; and Scuseria,G. E.; Phys. Rev. Lett., 2003, 91, 146401.

(35) CYLview, 1.ob; C. Y. Legault, Université de Sherbrooke, 2009 (http://www.cylview.org). 


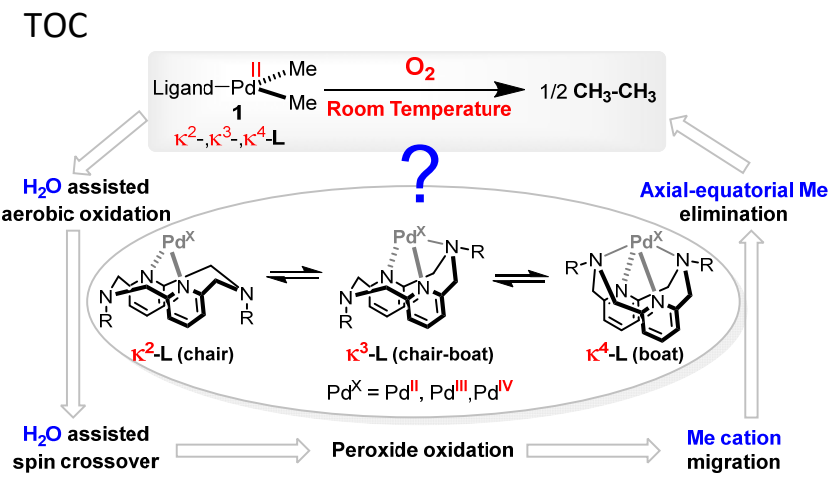

